\title{
Caste, Corruption and Political Competition in India
}

\author{
Avidit Acharya \\ Email: aachary3@z.rochester.edu \\ Departments of Political Science and Economics, \\ University of Rochester, Harkness \\ 327, Rochester NY 14627-0146 \\ John E. Roemer \\ Email: john.roemer@yale.edu \\ Departments of Political Science and Economics, \\ Yale University, PO Box 208301, New Haven CT 06520-8301
}

\section{Rohini Somanathan \\ Email:rohini@econdse.org \\ Department of Economics \\ Delhi School of Economics}

\section{Working Paper No. 241}




\title{
Caste, Corruption and Political Competition in India*
}

\author{
Avidit Acharya, John E. Roemer and Rohini Somanathan ${ }^{\dagger}$
}

January 14,2015

\begin{abstract}
Voters in India are often perceived as being biased in favor of parties that claim to represent their caste. We incorporate this caste bias into voter preferences and examine its influence on the distributive policies and corruption practices of the two major political parties in the North Indian state of Uttar Pradesh (U.P.). We begin with a simple two-party, two-caste model to show that caste bias causes political parties to diverge in their policy platforms and has ambiguous effects on corruption. We then develop the model to make it correspond more closely to political reality by incorporating class-based redistributive policies. We use survey data from U.P. that we collected in 2008-2009 to calibrate voter preferences and other model parameters. We then numerically solve for the model's equilibria, and conduct a counterfactual analysis to estimate policies in the absence of caste bias. Our model predicts that the Bahujan Samaj Party (BSP), which was in power at the time of our survey, would be significantly less corrupt in a world without caste-based preferences.
\end{abstract}

${ }^{*}$ We are grateful to numerous people and seminar audiences for their comments and suggestions on this project, especially Nirvikar Singh and E. Sridharan. We thank Bhartendu Trivedi and his team at Morsel for their outstanding support in helping us design the survey questionnaire and in implementing it across U.P. The Institute for Social and Policy Studies and the Macmillan Center for International and Area Studies, both at Yale University, provided generous financial support. Bhanu Shri and Hyesung Kim provided outstanding research assistance.

${ }^{\dagger}$ Acharya: Departments of Political Science and Economics, University of Rochester, Harkness 327, Rochester NY 14627-0146 (email: aachary3@z.rochester.edu); Roemer: Departments of Political Science and Economics, Yale University, PO Box 208301, New Haven CT 06520-8301 (email: john.roemer@yale.edu); Somanathan: Delhi School of Economics, University of Delhi, Delhi 110007, India (email: rohini@econdse.org). 


\section{Introduction}

Politics in India are intensely competitive. In the 48 elections held in major Indian states between 1989 and 1999, only one-quarter of sitting governments were re-elected (Kumar, 2004). In many of these states, such as Uttar Pradesh in the North and Tamil Nadu in the South, regional parties based on specific linguistic or ethnic identities have emerged. These parties now dominate politics at the state level, alternating power after each election. At the national level, only about half the seats in parliament are retained by incumbents, and many sitting M.P.s are not re-nominated in successive elections. ${ }^{1}$

It is difficult to reconcile this competition with two other well-known features of Indian politics, namely, rampant corruption and group-based voting. Political parties are regarded as the most corrupt among all state institutions and a fight against corruption is now at the center of a mass-movement. According to the Global Corruption Barometer Survey of 2013 by Transparency International, more than half of the 1,025 Indian respondents reported having paid a bribe in the past year. ${ }^{2}$ These coincident patterns are puzzling. Why do politicians not steal less and offer more to voters to win favor with the electorate? On the other hand, if social identities determine voting behavior, what limits the degree of corruption that parties engage in?

In this paper, we propose a model that addresses these questions in the Indian political system. Central to the model is some degree of "caste bias" in voter preferences. By this we mean that citizens have some preference to vote for a party that they see as representing their caste independent of the policy that the party is proposing. Such bias has been widely observed in voter behavior, and respondents in election surveys easily associate caste groups with particular parities. ${ }^{3}$ The difficulty in explaining electoral outcomes based on such identity politics lies in understanding how parties garner votes from outside their caste base, a question we focus upon here.

We first present a stylized 2-party 2-group model in which each of two groups of voters has a bias in favor of one of two parties. Each party decides its level of corruption, which is simply the fraction of the budget that does not get distributed to the electorate. The total budget available to each party is directly proportional to its vote share. We characterize the conditions under which a unique Nash equilibrium exists and we show that the equilibrium involves policy divergence in that parties choose dif-

\footnotetext{
${ }^{1}$ These facts are based on data downloaded from the website of the Election Commission of India (eci.nic.in).

${ }^{2}$ The Transparency International 2013 report is available at http://www.transparency.org.

${ }^{3}$ See our Table 2 in Section 4.
} 
ferent levels of corruption. Relative to a world with no caste bias, corruption is higher for the party favored in the aggregate by caste bias, and lower for the other party. With probabilistic voting a la Lindbeck and Weibull (1987), caste-based preferences therefore have ambiguous effects on corruption.

The fact that the effects of caste bias are ambiguous raises an empirical question: What is the effect of caste bias on the corruption of a particular political party? To answer this question, we proceed to develop our stylized model in a number of ways to make it better correspond to political reality. Our benchmark is the political scene in the northern state of Uttar Pradesh (U.P.), where we collected survey data in 20082009. Voters in our model now have both a caste identity and belong to one of three income classes: rich, middle or poor. Parties choose their level of corruption and decide how to distribute the remaining pie across these three classes. Constitutional restrictions do not allow the state to target resources directly to castes, yet most policies have direct implications for caste-wise welfare because of the correlation between caste and class. Class-based policies therefore determine the average transfer each caste group receives from each party.

We begin by using our survey data to estimate the bias of each caste towards each of the four major parties contesting elections in U.P. in recent years. Two of these, the Indian National Congress (INC) and the Bharatiya Janata Party (BJP), are national-level parties, and we assume that their policies are determined exogenously at the national level. We estimate the parties' policies using responses to questions in our survey which asked voters how each party distributes benefits across the different classes. Although the contest for power in U.P. has been four-cornered since the 1990s, the battle in state-level elections was increasingly between the two regional parties, the Bahujan Samaj Party (BSP) and the Samajwadi Party (SP), and we model our political game by allowing these two parties to choose policies strategically.

With a multi-dimensional policy space, Downsian equilibria do not generically exist. Thus, following Roemer (1999, 2001), we use party unanimity Nash Equilibrium (PUNE) as our equilibrium concept and characterize the set of such equilibria, each of which gives us the level of corruption and class-based distribution policies for each strategic party. We then perform a counterfactual analysis and ask how policies would change if all caste bias were eliminated. We do this through a comparative statics exercise for equilibria closest to the observed policies in U.P. We find that the BSP, which was in power at the time of our survey, would have much lower levels of corruption in the absence of any caste bias, while the corruption level of its principal rival, 
the SP, would increase slightly.

Our paper makes both a methodological and an empirical contribution to the literature on multi-dimensional policy choice in competitive political environments such as India. It is closely related to concurrent papers by Banerjee and Pande (2011) and Vaishnav (2012). Banerjee and Pande (2011) show that ethnic bias leads to the selection of lower quality politicians. They find that the winner from a geographic constituency in U.P. that is biased in favor of the winner's party (as measured by the party being pro-majority in its ethnic affiliation) is more likely to have a criminal record than the winner from the same party in a less biased jurisdiction. Vaishnav (2012) argues that in political jurisdictions reserved for particular castes, caste divisions are less salient, and thus it is less likely that parties put up candidates with a criminal background. While these papers complement our work, our approach is different in that we allow parties to use redistributive policies to win over voters from castes that they do not traditionally represent. We believe this is important in explaining political outcomes during the period of our study, since the BSP, which is identified as the party of the "Scheduled Castes," rose to power even though these castes form only $21 \%$ of the state's population. The BSP's victory in the State Assembly elections of 2007 was possible because it won the support of many "General Caste" voters, in particular Brahmins, through its proposed policies. ${ }^{4}$

The rest of this paper is organized as follows. Section 2 provides some background to U.P. politics and links trends in the state to national re-alignments and the rising salience of caste in public life. Section 3 develops the simple analytical model that motivates our research question, and provides some insight to our approach. Section 4 describes the data that we use in our estimation. Section 5 introduces the model that we use for the simulations. Section 6 calibrates this model to the factual data presented in Section 4. Section 7 computes the equilibria of the factual model with caste bias. Section 8 presents the main counterfactual analysis. We conclude the paper in Section 9 with a critical discussion of the assumptions of our model.

\section{State Politics in India}

Political allegiances and party configurations in India have gone through several phases since the first elections in 1952 (Sridharan 2002). Until 1967, the Indian National Congress (INC), which led the Independence movement, won the national assembly

\footnotetext{
${ }^{4}$ See "Brahmin Vote Helps Party of Low Caste Win in India" (May 12, 2007, New York Times).
} 
with two-thirds of the seats based on a plurality of votes typically between 40 and 45 per cent. During this period, elections to the national and state assemblies coincided, and we see a similar pattern of Congress Party domination in the states. Votes not received by the Congress were spread across a large number of other parties and Independents. The Congress vote and seat share fell over time and in the 1967 election the party held just over half the seats in the national assembly. In 1971, national and state assembly elections were held separately and there was a period of gradual consolidation of the smaller regional parties in most states. This eventually produced a two-party system within each state, with one of the other national parties forming the main opposition. In some cases, such as Kerala and West Bengal, the main opposition party was the Communist Party of India (CPI). In several north Indian states, including U.P., it was the nationalist and pro-Hindu Bharatiya Janta Party (BJP). Regional parties also gained ground in several states but in most instances, Congress remained one of the two leading parties.

The period starting in 1989 marked the steady decline of the Congress and the rise of state-based parties. ${ }^{5}$ This mirrors changes in many parts of the developing world where parties increasingly appealed to a few ethnic groups and voters looked to them for patronage and status (see Chandra, 2004, pp. 8-11, and the references therein). The growing strength of the BSP and the SP in U.P. is very much part of this wider trend. Both parties initially appealed to a much larger section of the population (bahujan samaj translates literally to "majority of society"). The top leadership of the BSP has, however, always come from among the Dalits or Scheduled Castes ("SCs"), and the party has come to be seen as representing their interests (Chandra 2004; Deliège 1999). Similarly, the SP is seen as representing the Yadavs and related castes which fall under the category of the "Other Backward Castes," ("OBCs"), which form $41 \%$ of U.P.'s population. ${ }^{6}$ By their sheer numbers, and their increasingly effective political organization, the OBCs have become an influential group in several states, including U.P. (Jaffrelot 2003; Yadav 2000).

U.P. is of special interest for the study of Indian politics because of the salience of caste-based rivalries and fierce contests for power (Chandra 2004; Banerjee and Pande 2011). Being by far the most populous state in the country, it has the largest number

\footnotetext{
${ }^{5}$ In the last five state elections (roughly 1990-2012), the Congress has not had a single victory in three major states: West Bengal, Tamil Nadu and U.P.

${ }^{6}$ The acronym OBC actually stands for "Other Backward Classes." However, since the definition of backwardness adopted by the Indian state has been caste-based, it is now more often used to refer to castes in this category and we refer to it in this sense throughout the paper.
} 
of seats in both state and national assemblies and no party has been willing to give up the competition to control it. While the SP and BSP emerged as strong regional parties, the two national parties, the INC and the BJP, have remained important, leading to a four-cornered battle for power. The agendas of these national parties in U.P. have been dictated by their national agendas, with religious nationalism being the core issue dividing them (Brass 2003; Varshney 2002; Wilkinson 2004).

The last two elections in U.P. have witnessed dramatic swings in seat shares. In 2007, the BSP won 206 out of 403 seats, the first absolute majority by a single party in U.P. in nearly fifteen years. This was a significant gain from the 98 seats they won in the 2003 elections, and a large margin over the SP, that came in second with only 97 seats. In the elections of 2012, however, the SP obtained an absolute majority in the State Assembly with 224 seats, diminishing the BSP to a distant second with only 80 seats. These swings cannot be explained purely by ethnic voting. Neither of the two parties has a large enough caste base for victory and the OBCs are almost twice as numerous as the SCs. The BSP victory in 2007 was achieved in part because it fielded several candidates from the General castes and adopted a more conciliatory platform towards these castes. This strategic behavior was widely noted in the popular press because it was these General castes towards which the BSP had historically been openly antagonistic. ${ }^{7}$

Caste issues have thus become more salient in Indian state politics, and our paper adds to the emerging literature that places these issues front and center in understanding patterns of political opinion and voting in India (Bhavnani 2013; Chandra 2004; Dunning and Nilekani 2013; and Lee 2013). We are also motivated by the theoretical perspective that we develop in the next section that ethnic biases can have substantial effects on policy outcomes, in particular the corruption of political parties. If our model applies to U.P., then we may have reason to believe that it also applies to other Indian states, and possibly other parts of the world where ethnic politics are known to distort policy outcomes (see, for example, Kramon and Posner 2012 and Franck and Rainer 2012). We now turn to developing our theoretical perspective more fully.

\footnotetext{
${ }^{7}$ The BSP took this to an extreme in its 2002 slogan "Thrash the Brahmin, the Bania and the Rajput" (translated from Tilak, tarazu aur talwar, Inko maro joote chaar (Jain 1996, p. 215).
} 


\section{A Simple Model}

In this section, we present a simple and stylized analytical model of probabilistic voting, a la Lindbeck and Weibull (2007), that motivates our research question: How would the political parties' corruption levels change if all political caste bias in U.P. were to be eliminated?

A continuum of citizens of unit mass are partitioned into two caste groups, called 1 and 2, with population shares $\nu$ and $1-\nu$ respectively. There are two political parties, labeled $A$ and $B$. Party $A$ is identified by voters with group 1 , and party $B$ with group 2. If party $r=A, B$ wins a fraction $\Phi^{r}$ of the total vote share, then it controls exactly a fraction $\Phi^{r}$ of the government's budget, which is normalized to 1 unit. $^{8}$ It can do two things with the budget: spend it on the populace, or take rents for itself. The distribution to the citizens, however, cannot be targeted: every citizen regardless of caste must receive the same amount of the good. Thus a party's policy can be represented by a number $x^{r}$, which is is the fraction of money under party $r$ 's control that it distributes to the populace, and $1-x^{r}$ is the fraction that it steals.

The fact that parties are associated with particular castes means that on average voters of each caste group have biases in favor of their associated party. Specifically, the payoff $u_{j}^{r}(\cdot)$ to a voter of ethnic group $j$ from voting for party $r$ is

$$
\begin{array}{ll}
u_{1}^{A}\left(x^{A}\right)=x^{A}+b_{1} & u_{2}^{A}\left(x^{A}\right)=x^{A} \\
u_{1}^{B}\left(x^{B}\right)=x^{B}+\varepsilon_{1} & u_{2}^{B}\left(x^{B}\right)=x^{B}+b_{2}+\varepsilon_{2}
\end{array}
$$

where $b_{1}, b_{2}>0$ are the average biases towards the favored parties in groups 1 and 2 and $\varepsilon_{1}$ and $\varepsilon_{2}$ are the realizations of random variables independently drawn across voters. We suppose that each $\varepsilon_{j}$ is uniform over an interval $[-d, d]$, and we denote this uniform CDF by $\mathbb{F}$.

Facing a policy pair $\left(x^{A}, x^{B}\right)$, a citizen of ethnic group 1 votes for party $A$ if and almost only if

$$
u_{1}^{A}\left(x^{A}\right)>u_{1}^{B}\left(x^{B}\right) \quad \Longleftrightarrow \quad \varepsilon_{1}<x^{A}-x^{B}+b_{1} \equiv \Delta_{1}\left(x^{A}, x^{B}\right)
$$

\footnotetext{
${ }^{8}$ In India, taxes are collected by the federal government and then allocated to the states, who decide how the money will be spent. State governments do not collect taxes. This suggests to us that modeling economic policy as the distribution of a resource (whose size does not vary with the corruption local parties), as opposed to a fiscal system of taxation and redistribution, is a reasonable approximation for U.P. We therefore adopt this modeling approach throughout the paper.
} 
and a citizen of ethnic group 2 votes for party $A$ if and almost only if

$$
u_{2}^{A}\left(x^{A}\right)>u_{2}^{B}\left(x^{B}\right) \quad \Longleftrightarrow \quad \varepsilon_{2}<x^{A}-x^{B}-b_{2} \equiv \Delta_{2}\left(x^{A}, x^{B}\right)
$$

If $\Delta_{j}\left(x^{A}, x^{B}\right), j=1,2$, lies in the interval $[-d, d]$, then the vote share of party $A$ from voters of caste $j$ is $\varphi_{j}^{A}\left(x^{A}, x^{B}\right)=\mathbb{F}\left(\Delta_{j}\left(x^{A}, x^{B}\right)\right)$ while the vote share of party $B$ from these voters is $\varphi_{j}^{B}\left(x^{A}, x^{B}\right)=1-\mathbb{F}\left(\Delta_{j}\left(x^{A}, x^{B}\right)\right)$. So the total vote share of party $A$, and consequently the fraction of government budget that it controls, is

$$
\begin{aligned}
\Phi^{A}\left(x^{A}, x^{B}\right) & =\nu \varphi_{1}^{A}\left(x^{A}, x^{B}\right)+(1-\nu) \varphi_{2}^{A}\left(x^{A}, x^{B}\right) \\
& =\frac{1}{2}+\frac{\nu \Delta_{1}\left(x^{A}, x^{B}\right)+(1-\nu) \Delta_{2}\left(x^{A}, x^{B}\right)}{2 d}
\end{aligned}
$$

while the total vote share of party $B$ is $\Phi^{B}\left(x^{A}, x^{B}\right)=1-\Phi^{A}\left(x^{A}, x^{B}\right)$.

Now, assume that the two parties are venal, meaning that their objective is to maximize the rents that they take. Then the the payoff of party $r$ from the policy pair $\left(\tilde{x}^{r}, x^{-r}\right)$ is

$$
\left(1-\tilde{x}^{r}\right) \cdot \Phi^{r}\left(\tilde{x}^{r}, x^{-r}\right)
$$

which is strictly concave in a party $r$ 's own policy $\tilde{x}^{r}$, for all policies of the the other party $x^{-r}$. This implies that we can compute the best response of party $r$ to policy $x^{-r}$ of the other party $-r$, by taking the first order condition for the maximization of (3). For the moment, we ignore the budget constraint that $\tilde{x}^{r}$ must be a number between 0 and 1 . The first order conditions for the two parties are then

$$
-\Phi^{r}\left(\tilde{x}^{r}, x^{-r}\right)+\left(1-\tilde{x}^{r}\right) \frac{\partial}{\partial \tilde{x}^{r}} \Phi^{r}\left(\tilde{x}^{r}, x^{-r}\right)=0, \quad r=A, B
$$

These are two equations in two unknowns. If the solution to these equations are numbers $\left(\tilde{x}^{A}, \tilde{x}^{B}\right)=\left(x^{A}, x^{B}\right) \in[0,1]^{2}$, and $\Delta_{1}\left(x^{A}, x^{B}\right), \Delta_{2}\left(x^{A}, x^{B}\right) \in[-d, d]$, then the solution constitutes a local Nash equilibrium of the policy announcement game. The solutions to the first order conditions are

$$
x^{A}=1-d-\frac{\nu b_{1}-(1-\nu) b_{2}}{3} \quad \text { and } \quad x^{B}=1-d+\frac{\nu b_{1}-(1-\nu) b_{2}}{3}
$$

Thus, if $d$ is small, and the biases $b_{1}$ and $b_{2}$ are small in comparison to $d$, then we have a local Nash equilibrium. ${ }^{9}$

\footnotetext{
${ }^{9}$ The equilibrium can be made global by scaling down all of the payoffs, e.g., by multiplying all of the payoffs $u_{j}^{r}(\cdot)$ by a number $\gamma>0$ that is small in comparison to $d$. This guarantees that $\Delta_{1}\left(x_{A}, x_{B}\right)$ and $\Delta_{2}\left(x_{A}, x_{B}\right)$ always lie inside the interval $[-d, d]$ for all feasible pairs $\left(x_{A}, x_{B}\right)$.
} 
Notice that the equilibrium features policy divergence: one party is always more corrupt than the other, except in knife-edge cases. ${ }^{10}$ Moreover, the equilibrium value of $x^{A}$ is decreasing in $b_{1}$ and increasing in $b_{2}$ while the equilibrium value of $x^{B}$ is increasing in $b_{1}$ and decreasing in $b_{2}$. As the political bias grows for the members of a particular group, the corruption level of their party increases while the corruption level of the other party decreases.

What happens when all caste bias in society is eliminated? In other words, what would happen if we were to lower both of the caste biases, $b_{1}$ and $b_{2}$, to 0 ? If it was originally the case that the aggregate caste bias in favor of party $A$ was larger than the aggregate caste bias in favor of party $B$ (i.e., if $\nu b_{1}>(1-\nu) b_{2}$ ), then eliminating all caste bias would lower the corruption of party $A$, but it would raise the corruption of party $B$. On the other hand, when party $B$ enjoys greater total caste bias (i.e., when $\left.\nu b_{1}<(1-\nu) b_{2}\right)$ then eliminating all caste bias would raise the corruption of party $A$ and lower the corruption of party $B$. The key insight of the model is that because both parties compete for votes from both caste groups, the party that enjoys greater total caste bias can afford to be more corrupt while the one that enjoys lower total caste bias must make up for its disadvantage by being less corrupt.

Party Factions. Our assumption that parties are venal rent-maximizers is motivated by the fact that many politicians from all of the four major political parties in U.P. have criminal records, most of which are corruption charges (Banerjee and Pande 2011; Vaishnav 2012). ${ }^{11}$ Nevertheless, assuming that the parties are purely venal does not account for the fact that parties may have multiple factions with differing objectives.

We now take account of this fact. Suppose that within each of the two parties there are two factions of politicians: the Venals and the Guardians. The objective of the Venals of party $r$ is to maximize the total amount that their party takes, as above. On the other hand, the objective of the Guardians of party $r$ is to maximize the average payoff of the constituents of their party. ${ }^{12}$ Since voting is probabilistic, the notion of

\footnotetext{
${ }^{10}$ This policy divergence result stands in contrast to the standard Downsian model of probabilistic voting which produces policy convergence. Unlike the Downsian model, our model has policy divergence because we model parties as venal. They are not Downsian parties that care only about vote share or probability of victory; instead they are rent-maximizers.

${ }^{11}$ For example, the following are the fractions of candidates with criminal records put up by each of the four major parties: BSP $(36.27 \%)$, SP (27.01\%), INC (21.60\%), BJP (23.05\%). These data are from "The criminalisation of Indian democracy" (May 2, 2007, Financial Times) and "Many with criminal past in polls." (April 28, 2007, The Hindu).

${ }^{12}$ These party factions are analogous, but not identical, to the party factions used in previous work
} 
constituency is statistical: the size of party $r$ 's constituency among caste $j$ voters at the policy pair $\left(x^{A}, x^{B}\right)$ is $\varphi_{j}^{r}\left(x^{A}, x^{B}\right)$. Thus, the payoffs that the Guardians of each of the two parties, $A$ and $B$, receive if their party $r$ unilaterally deviates to the policy $\tilde{x}^{r}$ from the policy pair $\left(x^{r}, x^{-r}\right)$ are, respectively, given by

$$
\begin{aligned}
& \Pi^{\mathcal{G} A}\left(\tilde{x}^{r} ;\left(x^{r}, x^{-r}\right)\right)=\nu \varphi_{1}^{A}\left(x^{A}, x^{B}\right)\left(\tilde{x}^{A}+b_{1}\right)+(1-\nu) \varphi_{2}^{A}\left(x^{A}, x^{B}\right)\left(\tilde{x}^{A}\right) \\
& \Pi^{\mathcal{G} B}\left(\tilde{x}^{r} ;\left(x^{r}, x^{-r}\right)\right)=\nu \varphi_{1}^{B}\left(x^{A}, x^{B}\right)\left(\tilde{x}^{B}\right)+(1-\nu) \varphi_{2}^{B}\left(x^{A}, x^{B}\right)\left(\tilde{x}^{B}+b_{2}\right)
\end{aligned}
$$

The key feature here is that the Guardians of each party evaluate the average payoff of the constituents of their party under the original policy pair $\left(x^{r}, x^{-r}\right)$, even though their party's deviation to policy $\tilde{x}^{r}$ would change the actual voting constituencies. In other words, the deviation payoffs of the Guardians reflect a form of "reference dependence" in which the policy pair that their party deviates from is taken to be the reference point. ${ }^{13}$ The payoff to the Venals of party $r$ when their party deviates to a policy $\tilde{x}^{r}$ from the policy pair $\left(x^{r}, x^{-r}\right)$ is denoted $\Pi^{\mathcal{V} r}\left(\tilde{x}^{r} ;\left(x^{r}, x^{-r}\right)\right)$, and defined to equal the quantity in (3). Thus, the Venals' payoffs are not reference dependent since $x^{r}$ does not appear on the right side of (3).

We refer to a party unanimity Nash equilibrium (PUNE) as a policy pair $\left(x^{A}, x^{B}\right)$ such that neither party $r=A, B$ can find a deviation that weakly improves the payoff of both of its factions, and strictly improves the payoff of at least one of the two factions. By an application of the Kuhn-Tucker Theorem, if the policies $\left(x^{A}, x^{B}\right)$ are a local PUNE then there exist a pair of nonnegative Lagrangian multipliers $\left(\alpha^{A}, \alpha^{B}\right)$ such that $\left(x^{A}, x^{B}\right)$ satisfies the following equilibrium first order conditions

$$
-\left.\frac{\partial \Pi^{\mathcal{V} r}\left(\tilde{x}^{r} ;\left(x^{r}, x^{-r}\right)\right)}{\partial \tilde{x}^{r}}\right|_{\tilde{x}^{r}=x^{r}}=\left.\alpha^{r} \cdot \frac{\partial \Pi^{\mathcal{G} r}\left(\tilde{x}^{r} ;\left(x^{r}, x^{-r}\right)\right)}{\partial \tilde{x}^{r}}\right|_{\tilde{x}^{r}=x^{r}}, r=A, B
$$

This states that a small change from the equilibrium policy $x^{r}$ of party $r$ will decrease the payoff of one of party $r$ 's factions if it increases the payoff of the other faction. ${ }^{14}$ Rearranging the the above equations, we can characterize the set of local "interior"

by Roemer (1999, 2001). Here, we have replaced the Opportunist (i.e., Downsian) faction of a party with the Venals. Given that 206 out of 403 politicians that won in the 2007 State Assembly elections had criminal records, we argue that this is an appropriate amendment.

${ }^{13}$ See, for instance, Köszegi and Rabin (2006) for a model of reference dependent utility.

${ }^{14}$ Note here that if $\alpha^{A}=\alpha^{B}=0$ at a particular PUNE $\left(x^{A}, x^{B}\right)$ then that PUNE is also a local Nash equilibrium of the previous model in which parties have only venal objectives (provided that $\left.\Delta_{1}\left(x^{A}, x^{B}\right), \Delta_{2}\left(x^{A}, x^{B}\right) \in[-d, d]\right)$. If $\alpha^{A}$ and $\alpha^{B}$ are small, then it is an $\epsilon$-local Nash equilibrium for a small value of $\epsilon$. 


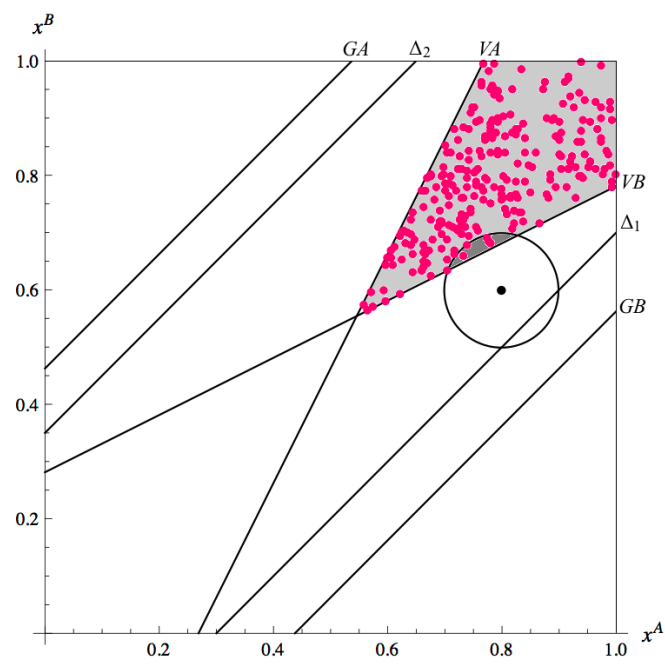

Figure 1. The set of feasible policies is depicted by the unit square with $x^{A}$ on the horizontal axis and $x^{B}$ on the vertical axis. We set $\nu=0.45, d=0.45, b_{1}=0.15$ and $b_{2}=0.1$ and characterize the set of local PUNEs as the gray shaded area, using the inequalities in (8). We also computed 257 candidates for PUNE by solving the equilibrium first order conditions given by (7); these are represented by the red dots. The black dot represents a hypothetical policy, and the circle encloses the set of policies that are within a distance of 0.1 units from it.

PUNEs with the following inequalities: ${ }^{15}$

$$
\begin{array}{r}
-\frac{\partial \Pi^{\mathcal{V} r}\left(\tilde{x}^{r} ;\left(x^{r}, x^{-r}\right)\right) /\left.\partial \tilde{x}^{r}\right|_{\tilde{x}^{r}=x^{r}}}{\partial \prod^{\mathcal{G} r}\left(\tilde{x}^{r} ;\left(x^{r}, x^{-r}\right)\right) /\left.\partial \tilde{x}^{r}\right|_{\tilde{x}^{r}=x^{r}}} \geq 0, r=A, B, \\
\Delta_{1}\left(x^{A}, x^{B}\right) \leq d, \text { and }-\Delta_{2}\left(x^{A}, x^{B}\right) \leq d
\end{array}
$$

The first line states that both of the Lagrangian multipliers, $\alpha^{A}$ and $\alpha^{B}$, are nonnegative. The inequalities in the second line guarantee that both $\Delta_{1}\left(x^{A}, x^{B}\right), \Delta_{2}\left(x^{A}, x^{B}\right) \in$ $[-d, d]$ by the fact that $b_{1}, b_{2}>0$. (This makes a PUNE "interior.") In Figure 1 , we depict the region of local PUNEs implied by the inequalities in (8). The lines labeled $G r, r=A, B$, represent the equations $\partial \Pi^{\mathcal{G} r}\left(\tilde{x}^{r} ;\left(x^{r}, x^{-r}\right)\right) /\left.\partial \tilde{x}^{r}\right|_{\tilde{x}^{r}=x^{r}}=0$. The lines labeled $V r$, represent $\partial \Pi^{\mathcal{V} r}\left(\tilde{x}^{r} ;\left(x^{r}, x^{-r}\right)\right) /\left.\partial \tilde{x}^{r}\right|_{\tilde{x}^{r}=x^{r}}=0$. And, the lines labeled $\Delta_{1}$ and

\footnotetext{
${ }^{15}$ If a policy pair is a local PUNE, then each party's policy maximizes the payoff of its Venals, subject to the constraint that the Guardians receive at least a certain payoff (see, e.g., Roemer 2001). Since the payoff of the Venals is strictly concave, and the constraint on the payoff to the Guardians defines a convex compact set, any local PUNE for which $\Delta_{1}\left(x^{A}, x^{B}\right), \Delta_{2}\left(x^{A}, x^{B}\right) \in[-d, d]$ must satisfy the inequalities in the first line of (8). The condition that $\Delta_{1}\left(x^{A}, x^{B}\right)$ and $\Delta_{2}\left(x^{A}, x^{B}\right)$ both lie in the interval $[-d, d]$ is equivalent to the two inequalities in the second line of $(8)$ (whenever $\left.b_{1}, b_{2} \geq 0\right)$ and is what makes a local PUNE "interior."
} 
Table 1. Respondents by Type

\begin{tabular}{lllll} 
& General & OBC & SC/ST & Total \\
\hline \hline Rich & 232 & 155 & 22 & 409 \\
Middle & 634 & 1145 & 342 & 2121 \\
Poor & 274 & 945 & 740 & 1959 \\
\hline Muslim & 289 & 380 & 4 & 673 \\
Women & 481 & 988 & 549 & 2018 \\
All & 1140 & 2245 & 1104 & 4489 \\
\hline
\end{tabular}

$\Delta_{2}$ represent $\Delta_{1}\left(x^{A}, x^{B}\right)-d=0$ and $\Delta_{2}\left(x^{A}, x^{B}\right)+d=0$, respectively. All of these lines are plotted in Figure 1 for parameter values $\nu=0.45, d=0.45, b_{1}=0.15$ and $b_{2}=0.1$. The set of local PUNEs is thus the gray shaded area.

As explained in Roemer (2001), the advantage of the PUNE approach with party factions is that it produces equilibria even in instances where the policy space is multidimensional. The is in contrast to other approaches, like the Downsian approach, in which parties are modeled as unitary actors having a single objective. The disadvantage of the PUNE approach is that it produces multiple equilibria, creating a challenge for doing comparative statics. ${ }^{16}$ Since our model of electoral competition in U.P. will feature a multidimensional policy space, we adopt the PUNE approach. We also develop a method of doing comparative statics, despite the problem of multiple equilibria, in Section 8. But before that, we describe the data that we will use to calibrate the model.

\section{Data}

Our data are from a household survey of 4680 voters that we randomly sampled from the official voter list in U.P. between July 2008 and February 2009. ${ }^{17}$ One of the last questions that we asked voters was

Q1. Which party do you think will be the best party for U.P.?

\footnotetext{
${ }^{16}$ To do our counterfactual analysis, we could set $b_{1}=b_{2}=0$ and then re-characterize the PUNE region as in Figure 1, but this does not tell us how particular equilibrium policies change with changes in caste bias; it only tells us how the entire PUNE region changes.

${ }^{17}$ Further details about the data, including our sampling methodology, are available upon request from the authors.
} 
Table 2. Party Representation of Caste Groups

\begin{tabular}{llllll} 
Q2. (other) & BSP & SP & INC & BJP & DK/NA \\
\hline \hline General & 227 & 161 & 201 & 825 & 318 \\
OBC & 200 & 625 & 30 & 47 & 215 \\
SC/ST & 1397 & 36 & 11 & 24 & 171 \\
\hline Q3. (own) & BSP & SP & INC & BJP & DK/NA \\
\hline \hline General & 172 & 165 & 179 & 443 & 179 \\
OBC & 512 & 1074 & 157 & 182 & 316 \\
SC/ST & 964 & 35 & 30 & 8 & 66 \\
\hline
\end{tabular}

Note: We also gave respondents the option to answer other parties, e.g. the RLD, but only 6 respondents in our restricted sample (and 9 in the full dataset) exercised this option for either question Q2 or Q3.

Since the model we consider in Section 5 is one in which voters decide among one of the four major parties in U.P. (the BSP, SP, INC and BJP), in all that follows (except the last two tables) we report data only for the subset of voters who answered one of these parties to question Q1.18

Before asking Q1, we started by asking our subjects a variety of questions beginning with descriptive data, such as religion, caste and caste group (i.e., "social category"). We also asked these subjects to place themselves on an economic ladder with ten rungs, where the rungs indicate levels of economic status. ${ }^{19}$ In this paper, we label respondents who placed themselves in one of the two bottom rungs as "poor;" those that placed themselves in the next four rungs as "middle;" and those that placed themselves in the top four rungs as "rich." Table 1 above reports the distribution of self-perceptions of economic class along with the numbers of Muslim and women in each caste category.

To understand how respondents perceived the caste loyalties of the political parties, we asked respondents the following question:

\footnotetext{
${ }^{18}$ Only 191 out of 4680 respondents did not answer one of these four parties to question Q1. Nevertheless, statistics for the full sample of respondents, including those that answered other parties, said they did not know, or refused to answer, are available upon request from the authors.

${ }^{19}$ We also asked a variety of objective questions aimed at measuring wealth, e.g. what the respondent's house is made of. In a separate analysis, we construct an objective measure of wealth by aggregating answers to these questions via factor analysis. There, we show that the agent's self perception of his economic status is highly correlated with this objective measure of wealth. The results are available upon request.
} 
Table 3. Salience of Economic Issues vis-a-vis Caste Issues

(Numbers of Resp. that said "I will never change my party" to Q4)

\begin{tabular}{lllll} 
By Party Identification & BSP & SP & INC & BJP \\
\hline \hline Respondents & 302 & 275 & 101 & 144 \\
& $(18.3 \%)$ & $(21.6 \%)$ & $(27.6 \%)$ & $(22.7 \%)$ \\
\hline \hline By Caste Category & General & OBC & SC/ST & \\
\hline \hline Respondents & 201 & 346 & 279 & \\
& $(17.6 \%)$ & $(15.4 \%)$ & $(25.3 \%)$ & \\
\hline
\end{tabular}

Note: For the purpose of this table, an individuals is "affiliated" with the party that he or she gave as the answer to Q3. The first row of percentages are the raw numbers above as a fraction of the total number of individuals who answered the given party to Q3. The second row of percentages are the raw numbers above as a fraction of the total number of respondents belonging to the that caste category.

Q2. What is the party of caste $X$ ?

where $X$ was a randomly chosen caste group that was not the group of the respondent. The entries in Table 2 are the numbers of respondents who answered the parties listed column-wise for the caste groups listed row-wise. We also asked respondents

Q3. What is the party of caste $Y$ ?

where $Y$ was the caste group to which the respondent belonged. The answers to this question are also reported in Table 2. The table also reports the numbers of respondents that said that there is no such party, or that the question is faulty, or that they don't know, or that simply refused to answer, all under the column DK/NA.

Answers to Q2 and Q3 were useful in constructing a measure of how strongly committed our respondents were to the party that they reported as representing their caste group. For example, we asked all respondents who answered different parties to questions Q2 and Q3 the following question:

Q4. Suppose [answer to Q3] proposes to spend Rs. 1000 on the development of your village. What is the minimum that [answer to Q2] would have to propose to spend on the development of your village so that you would want to vote for [answer to Q2] instead? 
Table 4. Views on Caste and Politics

\begin{tabular}{lllll} 
& BSP & SP & INC & BJP \\
\hline \hline Average & 443.43 & 494.74 & 517.47 & 419.32 \\
& $(256.45)$ & $(251.70)$ & $(261.85)$ & $(238.58)$ \\
\hline Respondents & 4382 & 4330 & 4067 & 4197 \\
\hline
\end{tabular}

In answers to this question, 1858 respondents gave answers above Rs. 1000, with an average answer across these respondents of Rs. 3085 (s.d.=4808); and 826 respondents gave the answer "I will never change my party," which was an option besides saying "I don't know" or refusing to answer. ${ }^{20}$ The modal answer among those that answered monetary amounts was Rs. 2000 (802 respondents), followed by Rs. 1500 (342 respondents) and Rs. 3000 (147 respondents). These numbers indicate that caste representation is important to most voters. Table 3 reports the breakdown of respondents by party identification and caste category that said that they would never change their party. It shows that 302 respondents, which is $18.3 \%$ of all respondents that identified their caste with the BSP, said that they would never leave the BSP. This is a larger number of respondents than for any other party. The table also shows that 279 members of the SC/ST category, which is $25.3 \%$ of all SC/ST respondents, said that they would never leave their party. This is also a larger number of respondents than for either of the other two caste categories.

In Table 4 we ask voters the following question about each of the four major parties listed column-wise:

Q5. If this party were in power in UP and had a budget of Rs. 1000 to spend, how much of that money do you think would actually get spent on the development of UP?

The high standard deviations in the responses reflect a lack of agreement about the quality of politicians, perhaps reflecting the voters' biased views towards parties. Nevertheless, we expect that for the most part opposing biases will cancel out, and that the averages are meaningful, or at least they are ordinally correct. (We comment more on this in Section 9.)

In Table 5, we ask the following question:

\footnotetext{
${ }^{20} 148$ respondents said "I don't know." 13 gave answers less than Rs. 1000 . The highest value reported was Rs. 60,000, but only 30 people answered amounts larger than Rs. 10,000.
} 
Table 5. Perceptions of Distribution Policy

\begin{tabular}{lllll} 
& Respondents & Rich & Middle & Poor \\
\hline \hline BSP & 4415 & 313.58 & 259.43 & 426.99 \\
& & $(205.61)$ & $(117.31)$ & $(229.67)$ \\
SP & 4391 & 317.64 & 317.41 & 364.95 \\
& & $(191.45)$ & $(141.50)$ & $(197.68)$ \\
INC & 4342 & 323.88 & 281.26 & 394.86 \\
& & $(180.60)$ & $(103.03)$ & $(190.45)$ \\
BJP & 4268 & 410.03 & 282.81 & 307.16 \\
& & $(203.34)$ & $(112.13)$ & $(182.94)$ \\
\hline
\end{tabular}

Q6. For each party listed in the first column, ask the respondent what s/he thinks the allocation of government benefits would be if the party was in power today. Have him/her allocate Rs. 1000 among a rich person, middle class person and poor person.

Again, we averaged the responses across respondents. These numbers will be used to calculate the average perceived policies of the parties, which will be used to calibrate the model. Finally, in Table 6 we report the answers to Q1 by type.

\section{Model}

We model an election circa 2008, a year after the BSP won a majority in the State Assembly elections, and a year before the INC won a plurality in the national level Lok Sabha elections. In our model, voters cast their ballots taking into account each party's distribution policy and corruption practice, and any caste bias they have in favor of or against a particular party.

In what follows, we introduce the parties and voters, and we define the set of policies for each party. We then define the voters' preferences and compute a party's vote share as a function of the profile of policies, and other parameters.

Parties and Voters. Our model includes the four prominent parties in Uttar Pradesh. These are the Bahujan Samaj Party (BSP), the Samajwadi Party (SP), the Indian 
Table 6. Choice of Party (Answers to Q1)

\begin{tabular}{lllll} 
& BSP & SP & INC & BJP \\
\hline \hline Rich General & 23 & 39 & 86 & 84 \\
Rich OBC & 23 & 69 & 45 & 18 \\
Rich SC/ST & 12 & 0 & 10 & 0 \\
Middle General & 81 & 122 & 207 & 224 \\
Middle OBC & 189 & 438 & 351 & 167 \\
Middle SC/ST & 223 & 26 & 79 & 14 \\
Poor General & 53 & 98 & 78 & 45 \\
Poor OBC & 241 & 331 & 272 & 101 \\
Poor SC/ST & 532 & 55 & 131 & 22 \\
\hline Total & 1377 & 1178 & 1259 & 675 \\
& $(30.7 \%)$ & $(26.2 \%)$ & $(28.1 \%)$ & $(15.0 \%)$ \\
\hline
\end{tabular}

National Congress (INC) and the Bharatiya Janata Party (BJP). ${ }^{21}$ Let $\mathcal{R}=\{\mathrm{BSP}$, SP, INC, BJP\} denote the set of parties in our model.

The voting population is a continuum of unit mass. Voters are divided into nine types that are indexed by the pair $(\tau, \rho)$, where $\tau \in\{R, M, P\}$ indicates class and $\rho \in\{G, O, S\}$ indicates caste. As usual, $R$ stands for rich, $M$ for middle, and $P$ for poor. For the caste groups, $G$ stands for General, $O$ for Other Backward Castes (OBC), and $S$ for Scheduled Castes/Scheduled Tribes (SC/ST). The set of nine types is denoted $\mathcal{T}$. Let $\nu_{\tau}$ be the fraction of class $\tau$, and $\nu_{\tau \rho}$ the fraction of type $(\tau, \rho)$, as calculated from our sample. The raw numbers are given in the upper half of Table 1.

Policies. A policy for party $r \in \mathcal{R}$ is a pair $\left(x^{r}, \lambda^{r}\right)$, where $(\mathrm{i}) x^{r}=\left(x_{R}^{r}, x_{M}^{r}, x_{P}^{r}\right)$ is a nonnegative vector of distributions to each member of each of the three classes, (ii) $\lambda^{r} \geq 0$ is the fraction of budget under party $r$ 's control that it will embezzle, and (iii) the following budget constraint is satisfied:

$$
\lambda^{r}+\sum_{\tau} \nu_{\tau} x_{\tau}^{r} \leq 1
$$

\footnotetext{
${ }^{21}$ Together these parties received $84.96 \%$ of the vote in 2007 , and won 376 out of 403 seats. The fifth best performing party, the Rastriya Lok Dal (RLD), received only $5.76 \%$ of the vote share and only 10 seats. We exclude the RLD from our analysis because it is a small regional party that contested only 254 seats, more than 95 fewer seats than the number of seats contested by any of the other four parties.
} 
We interpret this budget constraint as follows. The total budget of the government is normalized to 1 . If party $r$ wins $\Phi^{r}$ fraction of the votes, then it controls $\Phi^{r}$ fraction of the budget and will rule over exactly $\Phi^{r}$ fraction of the electorate. For simplicity, we assume that the mass of voters ruled by party $r$ is representative of the entire electorate in the sense that the distribution of types within this mass is the same as it is in the whole electorate. ${ }^{22}$ This implies that the budget constraint for party $r$ is $\lambda^{r} \Phi^{r}+\sum_{\tau}\left(\nu_{\tau} \Phi^{r}\right) x_{\tau}^{r} \leq \Phi^{r}$, which is equivalent to (BC) provided $\Phi^{r}>0$.

Because we have modeled the degree of corruption of a party as part of its policy, the policy space for all parties consists of points on and below the three-dimensional unit simplex in $\mathbb{R}_{+}^{4}$.

Voter Preferences. We assume that for a voter of type $(\tau, \rho)$, the deterministic part of her payoff from voting for party $r$ when it offers policy $\left(x^{r}, \lambda^{r}\right)$ is given by

$$
v_{\tau \rho}^{r}=\log x_{\tau}^{r}+b_{\rho}^{r}
$$

where $b_{\rho}^{r}$ is the "caste-bias" of a voter of caste $\rho$ towards party $r$. Note that voter preferences do not reflect a direct distaste for corruption. Voters care only about how much they can expect to receive from a party, $x_{\tau}^{r}$. They care about how much a party embezzles, $\lambda^{r}$, only inasmuch as it influences $x_{\tau}^{r}$ via the budget constraint (BC). ${ }^{23}$

In addition to the deterministic part of payoffs, we also assume that each voter receives a random preference shock in the following way. We partition each caste $\rho$ into four shock categories, where these categories are indexed by party. A voter of type $(\tau, \rho)$ who belongs to shock category $r$ receives a total payoff $u_{\tau \rho}^{s}=v_{\tau \rho}^{s}$ from voting for party $s \neq r$, and a total payoff

$$
u_{\tau \rho}^{r}=v_{\tau \rho}^{r}+\varepsilon_{\tau \rho}
$$

from voting for party $r$. Here, $\varepsilon_{\tau \rho}$ is a shock to the voter's preference, which we assume is the realization of a random variable distributed uniformly, and independently across

\footnotetext{
${ }^{22}$ This is a simplifying assumption made for parsimony. An alternative, more realistic, assumption would be that voters are divided into geographic districts that differ in the distribution of types within each district; and a party rules over only those districts where it obtains a plurality of the vote. In this case the distribution of types under a party's rule would be different from the distribution of types in the population because different types will vote in different numbers for each of the parties.

${ }^{23}$ Our formulation assumes that government benefits are targeted by class, but not caste. In reality, however, some economic policies are caste-based, such as employment reservations. We abstract from this interlinkage and assume that voters' perceptions of a party's position on such issues is absorbed into the caste bias term $b_{\rho}^{r}$. Additionally, by assuming that the biases $b_{\rho}^{r}$ are fixed, we are assuming that in the course of a single election parties cannot influence how much they are perceived by the voters to benefit a particular caste. (See Section 9 for more on this.)
} 
voters, on an interval $\left[-d_{\tau \rho}, d_{\tau \rho}\right]$. We denote the fraction of voters of caste $\rho$ that belong to shock category $r$ by $f_{\rho}^{r}$.

Vote Shares. Fix a policy profile $\left(x^{r}, \lambda^{r}\right)_{r \in \mathcal{R}}$. A voter of type $(\tau, \rho)$ casts her vote for party $r$ if

$$
u_{\tau \rho}^{r}>u_{\tau \rho}^{s} \quad \forall s \neq r .
$$

Since voting is probabilistic, we can define the probability that (11) holds. The probability that a voter of type $(\tau, \rho)$ and shock category $r \neq s, t$ prefers party $s$ over party $t$ is $\mathbb{P}\left[s \succ_{\tau \rho}^{r} t\right]=1$ if $v_{\tau \rho}^{s}>v_{\tau \rho}^{t}$, and 0 if the reverse inequality holds. Since $\varepsilon_{\tau \rho}$ is distributed uniformly on $\left[-d_{\tau \rho}, d_{\tau \rho}\right]$, the probability that she prefers party $r$ to party $s \neq r$ is

$$
\mathbb{P}\left[r \succ_{\tau \rho}^{r} s\right]= \begin{cases}0 & \text { if } v_{\tau \rho}^{r}-v_{\tau \rho}^{s}<-d_{\tau \rho} \\ \frac{1}{2}+\frac{v_{\tau \rho}^{r}-v_{\tau \rho}^{s}}{2 d_{\tau \rho}} & \text { if } v_{\tau \rho}^{r}-v_{\tau \rho}^{s} \in\left[-d_{\tau \rho}, d_{\tau \rho}\right] \\ 1 & \text { if } v_{\tau \rho}^{r}-v_{\tau \rho}^{s}>d_{\tau \rho}\end{cases}
$$

while the probability $\mathbb{P}\left[s \succ_{\tau \rho}^{r} r\right]$ that she prefers party $s$ to party $r$ is the complementary probability. If the set of voters that are indifferent between any two parties is at most measure zero (which will be the case whenever there is policy divergence), then these probabilities are sufficient to compute the vote shares of the four parties, as follows.

Let $\omega_{\tau \rho}=\left(\left(b_{\rho}^{s}, f_{\rho}^{s}\right)_{s \in \mathcal{R}}, d_{\tau \rho}\right)$ denote the profile of relevant parameters for type $(\tau, \rho)$. A simple derivation shows that a voter of type $(\tau, \rho)$ votes for party $r$ with probability: ${ }^{24}$

$$
\begin{aligned}
\varphi_{\tau \rho}^{r}\left(x^{r}, x^{-r} ; \omega_{\tau \rho}\right)=f_{\rho}^{r} & \sum_{s \in \mathcal{R} \backslash\{r\}}\left(\mathbb{P}\left[r \succ_{\tau \rho}^{r} s\right] \prod_{t \in \mathcal{R} \backslash\{r, s\}} \mathbb{P}\left[s \succ_{\tau \rho}^{r} t\right]\right) \\
& +\sum_{s \in \mathcal{R} \backslash\{r\}} f_{\rho}^{s}\left(\mathbb{P}\left[r \succ_{\tau \rho}^{s} s\right] \prod_{t \in \mathcal{R} \backslash\{r, s\}} \mathbb{P}\left[r \succ_{\tau \rho}^{s} t\right]\right) .
\end{aligned}
$$

Since there is a continuum of voters in each type, this is also party $r$ 's vote share within type $(\tau, \rho)$. By letting $\omega=\left(\left(b_{\rho}^{s}, f_{\rho}^{s}\right)_{s \in \mathcal{R}},\left(d_{\tau \rho}\right)_{\tau=R, M, P}\right)_{\rho=G, O, S}$ denote all of the parameters of the model, we can write the total vote share of party $r$ as

$$
\Phi^{r}\left(x^{r}, x^{-r} ; \omega\right)=\sum_{(\tau, \rho)} \nu_{\tau \rho} \varphi_{\tau \rho}^{r}\left(x^{r}, x^{-r} ; \omega_{\tau \rho}\right)
$$

${ }^{24}$ This is derived by noting that a voter of type $(\tau, \rho)$ belonging to shock category $s \neq r$ prefers party $r$ to all other parties with probability $\mathbb{P}\left[r \succ_{\tau \rho}^{s} s\right] \prod_{t \in \mathcal{R} \backslash\{r, s\}} \mathbb{P}\left[r \succ_{\tau \rho}^{s} t\right]$. If she belongs to shock category $r$, she prefers party $r$ to all other parties with probability $\sum_{s \in \mathcal{R} \backslash\{r\}} \mathbb{P}\left[r \succ_{\tau \rho}^{r} s\right] \prod_{t \in \mathcal{R} \backslash\{r, s\}} \mathbb{P}\left[s \succ_{\tau \rho}^{r} t\right]$. We then sum over all of the possible ways that she prefers party $r$ to all other parties, keeping in mind that within a type $(\tau, \rho)$ the fraction of shock category $t$ is $f_{\rho}^{t}$. 


\section{Calibration}

We calibrate the model by targeting vote shares. Our calibration estimates the parameters $\omega_{\rho}=\left(\left(b_{\rho}^{s}, f_{\rho}^{s}\right)_{s \in \mathcal{R}},\left(d_{\tau \rho}\right)_{\tau=R, M, P}\right)$ for each caste $\rho$ by minimizing the populationweighted sum of differences between fitted and actual vote shares by caste. We describe this procedure in detail as follows.

Let $g_{\tau \rho}^{r}$ denote the fraction of respondents of type $(\tau, \rho)$ that said that party $r$ was the best party for U.P. out of a total that chose one of the four parties in $\mathcal{R}$. These are computed from the entries of Table 6 . Next, set $1-\lambda^{r}$ equal to the entries of Table 4 (divided by 1000), and $y_{\tau}^{r}$ equal to the entries of Table 5 (also divided by 1000). Thus, $\lambda^{r}$ is the fraction of budget under party $r$ 's control that the average voter said would not get spent on the development of U.P. We interpret this as the fraction of budget that the party takes, i.e. the corruption level of the party. We interpret $y_{\tau}^{r}$ as the fraction of the remaining budget that party $r$ distributes to a voter of class $\tau$ when the party distributes the remaining funds to three voters, one from each class. Since the entries of Table 5 are amounts received by individual members of the three classes, we define the distribution policy components $x_{\tau}^{r}$ by correcting for the population shares of the three classes. More precisely, we fix the distribution components $x_{\tau}^{r}$ of party's policy for each of the four parties by setting

$$
x_{\tau}^{r}=\frac{\left(1-\lambda^{r}\right) y_{\tau}^{r}}{\sum_{\tau^{\prime}} \nu_{\tau^{\prime}} y_{\tau^{\prime}}^{r}}, \quad \tau=R, M, P, \quad r \in \mathcal{R}
$$

Thus, we have fixed a profile of policies $\left(x^{r}, \lambda^{r}\right)_{r \in \mathcal{R}}$ using our data. Keeping this policy profile fixed, we numerically solve the following problem for each caste $\rho:{ }^{25}$

$$
\min _{\omega_{\rho}} \sum_{r \in \mathcal{R}} \sum_{\tau} \nu_{\tau \rho}\left|g_{\tau \rho}^{r}-\varphi_{\tau \rho}^{r}\left(x^{r}, x^{-r} ; \omega_{\tau \rho}\right)\right|
$$

subject to the normalization $b_{\rho}^{\mathrm{BJP}}=0$, and the constraints

$$
\sum_{s \in \mathcal{R}} f_{\rho}^{s}=1 \forall \rho, d_{\tau \rho} \geq 0 \forall(\tau, \rho) \text {, and } f_{\rho}^{s} \geq 0 \forall \rho, \forall s \in \mathcal{R}
$$

A few comments are in order. First, since the utilities for the voters are ordinal, the normalization $b_{\rho}^{\mathrm{BJP}}=0$ is without loss of generality. Second, since we solve the above problem for each caste $\rho$, we solve three different minimization problems. Finally, since we minimize the population-weighted sum of differences between fitted and actual vote

\footnotetext{
${ }^{25}$ Note that $\omega_{\rho}$ contains exactly the same parameters as $\left(\omega_{\tau \rho}\right)_{\tau=R, M, P}$. So minimizing the objective function in (Calib- $\rho$ ) over $\omega_{\rho}$ is the same as minimizing it over $\left(\omega_{\tau \rho}\right)_{\tau=R, M, P}$. The problems (Calib- $\left.\rho\right)$, $\rho=G, O, S$, were solved in Mathematica 8 using the method of "simulated annealing."
} 
Table 7. Calibrated Parameter Values

\begin{tabular}{|c|c|c|c|c|c|c|c|c|c|}
\hline & $b_{G}^{\mathrm{BSP}}$ & $b_{G}^{\mathrm{SP}}$ & $b_{G}^{\mathrm{INC}}$ & $b_{O}^{\mathrm{BSP}}$ & $b_{O}^{\mathrm{SP}}$ & $b_{O}^{\mathrm{INC}}$ & $b_{S}^{\mathrm{BSP}}$ & $b_{S}^{\mathrm{SP}}$ & $b_{S}^{\mathrm{INC}}$ \\
\hline \multirow[t]{2}{*}{ Caste Bias $\left(b_{\rho}^{r}\right)$} & -1.73 & 0.45 & 0.38 & -0.86 & 0.06 & -0.03 & 0.33 & -0.45 & -0.16 \\
\hline & $f_{G}^{\mathrm{BSP}}$ & $f_{G}^{\mathrm{SP}}$ & $f_{G}^{\mathrm{INC}}$ & $f_{O}^{\mathrm{BSP}}$ & $f_{O}^{\mathrm{SP}}$ & $f_{O}^{\mathrm{INC}}$ & $f_{S}^{\mathrm{BSP}}$ & $f_{S}^{S P}$ & $f_{S}^{\mathrm{INC}}$ \\
\hline \multirow[t]{2}{*}{ Category Sizes $\left(f_{\rho}^{r}\right)$} & 0.07 & 0.10 & 0.50 & 0.15 & 0.03 & 0.48 & 0.50 & 0.04 & 0.00 \\
\hline & $d_{R G}$ & $d_{M G}$ & $d_{P G}$ & $d_{R O}$ & $d_{M O}$ & $d_{P O}$ & $d_{R S}$ & $d_{M S}$ & $d_{P S}$ \\
\hline \multirow[t]{2}{*}{ Distributions $\left(d_{\tau \rho}\right)$} & 1.17 & 0.86 & 1.15 & 0.62 & 0.94 & 0.40 & 0.46 & 0.69 & 1.18 \\
\hline & & & & \multicolumn{2}{|c|}{$($ Calib- $G)$} & \multicolumn{2}{|c|}{$($ Calib- $O)$} & \multicolumn{2}{|c|}{$($ Calib-S $)$} \\
\hline \multirow{2}{*}{\multicolumn{2}{|c|}{ Fit $\left(\sum_{r} \sum_{\tau} \nu_{\tau}\left|g_{\tau \rho}^{r}-\varphi_{\tau \rho}^{r}\right|\right)$}} & & & \multicolumn{2}{|c|}{.016} & \multicolumn{2}{|c|}{.045} & \multicolumn{2}{|c|}{.009} \\
\hline & & \multicolumn{2}{|c|}{$\mathrm{BSP}$} & \multicolumn{2}{|c|}{$\mathrm{SP}$} & \multicolumn{2}{|c|}{ INC } & \multicolumn{2}{|c|}{ BJP } \\
\hline \multicolumn{2}{|c|}{ Fitted Vote Shares $\left(\Phi^{r}\right)$} & \multicolumn{2}{|c|}{0.292} & \multicolumn{2}{|c|}{0.259} & \multicolumn{2}{|c|}{0.281} & \multicolumn{2}{|c|}{0.169} \\
\hline \multicolumn{2}{|c|}{ Actual Shares $\left(\sum_{\tau \rho} \nu_{\tau \rho} g_{\tau \rho}^{r}\right)$} & \multicolumn{2}{|c|}{0.307} & \multicolumn{2}{|c|}{0.262} & \multicolumn{2}{|c|}{0.280} & \multicolumn{2}{|c|}{0.150} \\
\hline
\end{tabular}

Note: Since the calibration set $b_{\rho}^{\mathrm{BJP}}=0$ for all $\rho$, the table reports only the caste biases for the other three parties. Similarly, since $f_{\rho}^{\mathrm{BJP}}=1-\sum_{r \neq \mathrm{BJP}} f_{\rho}^{r}$, we do not report $f_{\rho}^{\mathrm{BJP}}$.

shares, we are trading off quality of fit for smaller population types in favor of better fits for larger population types. ${ }^{26}$

Table 7 reports our estimated solutions to the problems (Calib- $\rho$ ). As the table indicates, SC/ST voters are most biased in favor of the BSP and most biased against the SP. On the other hand, OBC voters are most biased in favor of the SP, and most biased against the BSP. These results are consistent with the general impression of our respondents in Table 2. The estimates in Table 7 also suggest that the General castes are biased against the BSP in favor of the SP and INC. This result is somewhat surprising given that our respondents reported the BJP to be most favorable to the General castes; however, the fact that General castes are not perceived as having strong ties to any party is consistent with our discussion of U.P. politics in Section 2. ${ }^{27}$ The table also indicates that the calibration slightly overestimates the vote share of the BJP at the expense of the BSP; otherwise the fit is fairly accurate. For the rest of the

\footnotetext{
${ }^{26}$ Additionally, note that the objective function in (Calib- $\rho$ ) effectively contains nine terms. This is because we are summing over three types, and effectively three parties, since the vote share of one of the parties is determined from the other three by the fact that they all must sum to 1 . For each problem, we are effectively minimizing over nine variables, since the size of one of the shock categories $f_{\rho}^{s}$ will be determined from the other three by the constraint that all four must add to 1.

${ }^{27}$ One cannot directly compare the magnitudes of these biases across castes because the effects of biases on voting behavior are relative to the distribution parameter $d_{\tau \rho}$.
} 
paper (except in Section 8) we set the parameters $\left(\omega_{\rho}\right)_{\rho=G, O, S}$ equal to their calibrated values in Table 7.

\section{Political Equilibrium}

Because the INC and BJP are national parties, we assume that their policies have been set nationally and are fixed as far as the state-level electoral competition in U.P. goes. In other words, their policies are exogenous and we set them equal to the estimates calculated from the data in equation (15) and values of $\lambda^{\mathrm{INC}}$ and $\lambda^{\mathrm{BJP}}$ used in the calibration of the previous section. The BSP and SP, on the other hand, are strategic parties and their policies are determined in equilibrium, as we explain next.

As in the simple model of Section 3, we assume that there are two competing factions in each of the two strategic parties: the Guardians and the Venals. The Guardians want to choose a policy that maximizes the average payoff of the constituents of their party. Again, voting is probabilistic so the notion of constituency is statistical: here, the size of party $r$ 's constituency among type $(\tau, \rho)$ at a particular policy profile is precisely equal to the share of votes from that type, $\varphi_{\tau \rho}^{r}$ at that profile. Likewise, the Venals want to choose a policy that maximizes the amount of government funds that their party takes following the election.

More formally, fix a policy profile $\left(x^{s}, \lambda^{s}\right)_{s \in \mathcal{R}}$. The payoffs from a deviation to the policy $\left(\tilde{x}^{r}, \tilde{\lambda}^{r}\right)$ from the profile $\left(x^{s}, \lambda^{s}\right)_{s \in \mathcal{R}}$ for the Guardians and Venals of party $r=$ BSP, SP are respectively

$$
\begin{aligned}
& \Pi^{\mathcal{G} r}\left(\tilde{x}^{r}, \tilde{\lambda}^{r} ;\left(x^{s}, \lambda^{s}\right)_{s \in \mathcal{R}}\right)=\sum_{(\tau, \rho)} \nu_{\tau \rho} \varphi_{\tau \rho}^{r}\left(x^{r}, x^{-r} ; \omega_{\tau \rho}\right)\left(\log \tilde{x}_{\tau}^{r}+b_{\rho}^{r}\right) \\
& \Pi^{\mathcal{V} r}\left(\tilde{x}^{r}, \tilde{\lambda}^{r} ;\left(x^{s}, \lambda^{s}\right)_{s \in \mathcal{R}}\right)=\tilde{\lambda}^{r} \cdot \Phi^{r}\left(\tilde{x}^{r}, x^{-r} ; \omega\right)
\end{aligned}
$$

As before, the Guardians evaluate the average payoff of the constituents of their party under the original policy profile $\left(x^{s}, \lambda^{s}\right)_{s \in \mathcal{R}}$, even though their deviation to policy $\left(\tilde{x}^{r}, \tilde{\lambda}^{r}\right)$ would change the actual voting constituencies. The Venals care only about their party's vote share and corruption policy.

Definition of Equilibrium. A party unanimity Nash equilibrium (PUNE) is a policy profile $\left(x^{r}, \lambda^{r}\right)_{r \in \mathcal{R}}$ consisting of the fixed policies $\left(x^{\mathrm{INC}}, \lambda^{\mathrm{INC}}\right)$ and $\left(x^{\mathrm{BJP}}, \lambda^{\mathrm{BJP}}\right)$ and a pair of policies $\left(x^{\mathrm{BSP}}, \lambda^{\mathrm{BSP}}\right)$ and $\left(x^{\mathrm{SP}}, \lambda^{\mathrm{SP}}\right)$ such that for neither party $r=\mathrm{BSP}, \mathrm{SP}$, is there a deviation $\left(\tilde{x}^{r}, \tilde{\lambda}^{r}\right)$ at which 
(i) $\Pi^{\mathcal{G} r}\left(\tilde{x}^{r}, \tilde{\lambda}^{r} ;\left(x^{s}, \lambda^{s}\right)_{s \in \mathcal{R}}\right) \geq \Pi^{\mathcal{G} r}\left(x^{r}, \lambda^{r} ;\left(x^{s}, \lambda^{s}\right)_{s \in \mathcal{R}}\right)$, and

(ii) $\Pi^{\mathcal{V} r}\left(\tilde{x}^{r}, \tilde{\lambda}^{r} ;\left(x^{s}, \lambda^{s}\right)_{s \in \mathcal{R}}\right) \geq \Pi^{\mathcal{V} r}\left(x^{r}, \lambda^{r} ;\left(x^{s}, \lambda^{s}\right)_{s \in \mathcal{R}}\right)$

with at least one of the two inequalities strict. This definition states that a policy profile $\left(x^{s}, \lambda^{s}\right)_{s \in \mathcal{R}}$ is a PUNE if neither the BSP's nor the SP's two factions can improve their utilities, given the policies that the other three parties are proposing.

One may view a PUNE as a pair of policies, one for each party, at which the two factions in each party have bargained to a proposal for their party, taking the other party's policy as given. The pair of factions in each party has exhausted the gains from trade between them, conditional on the other party's proposal.

By an application of the Kuhn-Tucker Theorem, if the policies $\left(x^{\mathrm{BSP}}, \lambda^{\mathrm{BSP}}\right)$ and $\left(x^{\mathrm{SP}}, \lambda^{\mathrm{SP}}\right)$ are part of a PUNE, then there is a pair of nonnegative Lagrangian multipliers $\left(\alpha^{\mathrm{BSP}}, \alpha^{\mathrm{SP}}\right)$ such that the policy profile $\left(x^{s}, \lambda^{s}\right)_{s \in \mathcal{R}}$ satisfies the equations ${ }^{28}$

$$
\begin{aligned}
-\nabla_{x} \Pi^{\mathcal{V} r} & \left.\left(\tilde{x}^{r}, 1-\sum_{\tau} \nu_{\tau} \tilde{x}_{\tau}^{r} ;\left(x^{s}, \lambda^{s}\right)_{s \in \mathcal{R}}\right)\right|_{\tilde{x}^{r}=x^{r}} \\
& =\left.\alpha^{r} \cdot \nabla_{x} \Pi^{\mathcal{G} r}\left(\tilde{x}^{r}, 1-\sum_{\tau} \nu_{\tau} \tilde{x}_{\tau}^{r} ;\left(x^{s}, \lambda^{s}\right)_{s \in \mathcal{R}}\right)\right|_{\tilde{x}^{r}=x^{r}}, r=\text { BSP, SP } \quad \text { (E-FOC) }
\end{aligned}
$$

where the gradient operator $\nabla_{x}$ in these equations applies the derivative with respect to each of the three distribution components of policy $\left(x_{R}^{r}, x_{M}^{r}, x_{P}^{r}\right)$. The system of equilibrium first order conditions (E-FOC) comprises six equations in eight unknowns: the unknowns are the three policy components $\left(x_{R}^{r}, x_{M}^{r}, x_{P}^{r}\right)$, for each of the two strategic parties, $r=\mathrm{BSP}$, SP, and the two Lagrangian multiplies, $\alpha^{\mathrm{BSP}}$ and $\alpha^{\mathrm{SP}}$.

Estimation Procedure. Because the system of equations (E-FOC) has six equations in eight unknowns, we expect that if a solution to the system exists then there will in fact be a two-dimensional manifold of solutions in $\mathbb{R}_{+}^{8}$; in other words, there are multiple equilibria. One way to reduce (E-FOC) to a system of six equations in six unknowns would be to set $\alpha^{\mathrm{BSP}}=\alpha^{\mathrm{SP}}=0$. If a solution to the system exists with these values of the Lagrangian multipliers, then it is a candidate for a Nash equilibrium of the policy-announcement game in which parties have purely venal objectives, exactly as in the simple model of Section 3. We searched for such a solution, and were unable to find one. This is to be expected, since it is well-known that Nash equilibria generically fail to exist when the policy-space is multi-dimensional and the parties are Downsian. ${ }^{29,30}$

\footnotetext{
${ }^{28}$ The budget constraint does not appear in the Lagrangian in this formulation because it has been used to solve for one of the policies in terms of the others.

${ }^{29}$ The parties are not exactly Downsian here, but the Venal faction does indirectly care about its party's vote share, which determines the maximum amount that the party can embezzle.

${ }^{30}$ Even under our assumption of probabilistic voting a la Lindbeck and Weibull (1987), Downsian
} 

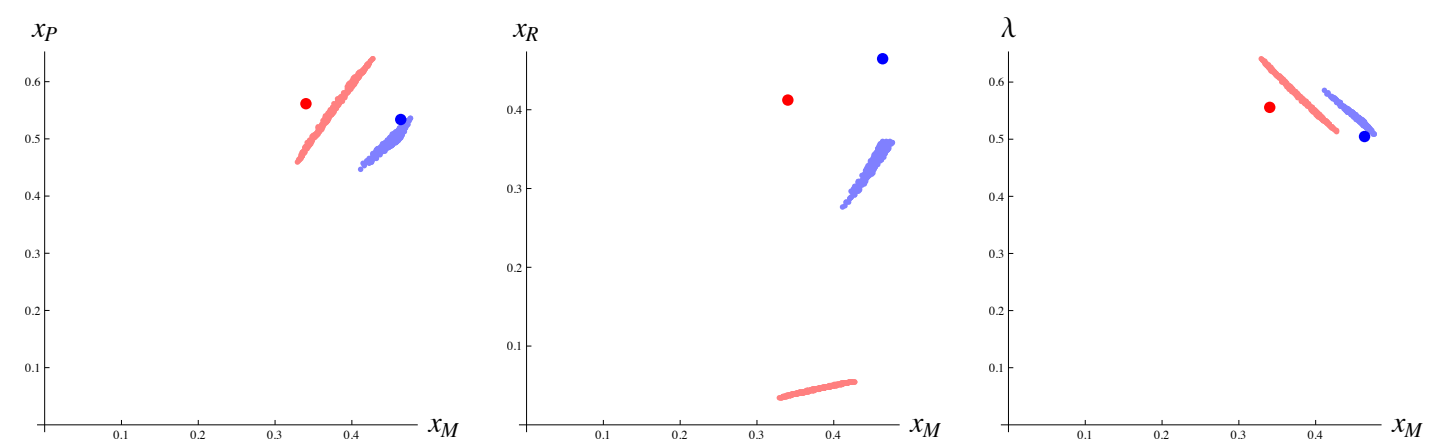

Figure 2. (a) [left] Projection of cPUNEs onto the $x_{M}-x_{P}$ plane. (b) [middle] Projection of cPUNEs onto the $x_{M}-x_{R}$ plane. (c) [right] Projection of cPUNEs onto the $x_{M^{-}} \lambda$ plane. Larger brighter dots indicate the "actual" policies of the BSP and SP, in red and blue respectively. Smaller lighter dots indicate cPUNE policies of the BSP and SP, in red and blue respectively.

Another approach is to characterize the manifold of equilibria using inequalities. Since the system of equations (E-FOC) is analogous to the first order conditions in equation (7) of Section 3's simple model, we can, in principle, derive inequalities like those in (8) to characterize the manifold of equilibrium candidates for the present model. Instead, our strategy will be to compute candidates for PUNE by numerically estimating solutions to the equilibrium first order conditions (E-FOC). This is analogous to what we did for the simple model in Section 3. There, we computed candidate equilibria by solving the first order conditions in (7), and depicted them as red points in Figure 1. The fact that these solutions cover the set of equilibria (the gray region) in Figure 1 suggests that we can characterize the set of equilibria this way. We numerically estimated solutions to the equilibrium first order conditions (E-FOC) via the secant method of gradient descent.

Estimates. We found 2593 distinct solutions to the system (E-FOC). These solutions are thus candidates for PUNE. Some of these candidate equilibria are depicted in Figure 1. Figure 2(a) on the left is the projection onto the $x_{M}-x_{P}$ plane, Figure $2(\mathrm{~b})$ in the middle is the projection onto the $x_{M}-x_{R}$ plane, and Figure 2(c) on the right is the projection onto the $x_{M^{-}} \lambda$ plane. The two larger and brighter dots in each of the projections indicate the "actual" policies of the BSP and SP in red and blue respectively; that is, they represent the values of $\left(x_{\tau}^{r}\right)_{\tau=R, M, P}$ and $\lambda^{r}$ for each party $r=$

equilibrium exists only under some very restrictive conditions that are unlikely to be satisfied following a calibration exercise like the one in this paper. Duggan (2012) analyzes these conditions. 
Table 8. Summary Statistics for Various Classes of Equilibria

\begin{tabular}{lcccccccc} 
& $x_{R}^{\mathrm{BSP}}$ & $x_{M}^{\mathrm{BSP}}$ & $x_{P}^{\mathrm{BSP}}$ & $\lambda^{\mathrm{BSP}}$ & $x_{R}^{\mathrm{SP}}$ & $x_{M}^{\mathrm{SP}}$ & $x_{P}^{\mathrm{SP}}$ & $\lambda^{\mathrm{SP}}$ \\
\hline \hline "Actual" & .412 & .341 & .561 & .557 & .465 & 464 & .534 & .505 \\
Mean cPUNE & .045 & .376 & .550 & .578 & .334 & .453 & .499 & .538 \\
Mean vcPUNE & .045 & .376 & .547 & .579 & .352 & .465 & .512 & .525 \\
Mean vcPUNE $_{0}$ & .202 & .717 & .712 & .332 & .282 & .420 & .557 & .533 \\
\hline
\end{tabular}

BSP, SP, computed from our survey data in the calibration exercise of Section 6. The lighter and smaller dots indicate candidate equilibrium policies for the BSP and SP in red and blue respectively. These figures depict only the 354 candidate PUNEs that are within a Euclidean distance of 0.135 units of the actual policies in $\mathbb{R}_{+}^{6} \cdot{ }^{31}$ We refer to these candidate PUNEs that are depicted in Figure 2 as cPUNEs ("c" for being "close" to the actual policies).

Figure 2(a) shows that as a party distributes more to the poor in cPUNEs, it distributes more to the middle class as well. Figure 2(b) shows that as a party distributes more to either the poor or the middle class in cPUNEs, it distributes more to the rich as well. Figure 2(c), however, depicts the key tradeoff: as a party embezzles more in cPUNEs, it distributes less to the populace. The figures indicate that our equilibrium estimates are close to the actual policies on all components except the shares received by the rich. This may not be surprising given that the rich form only $9.11 \%$ of the population (whereas the middle class and poor form $47.25 \%$ and $43.64 \%$ respectively) so they receive a much smaller weight in the calibration exercise of Table 7.

The 354 cPUNEs that are depicted in Figure 2 are not all very close to the actual policies depicted by the larger brighter dots. In the counterfactual analysis that follows, we therefore restrict our attention to the 40 cPUNEs that are within the smaller Euclidean distance of 0.06 units of the actual policies in $\mathbb{R}_{+}^{6}$. We refer to these as vcPUNEs ("vc" for "very close" to the actual policies). We give descriptive information on cPUNEs and vcPUNEs in the second and third rows of Table 8.

\footnotetext{
${ }^{31}$ The "actual" policies of the BSP and SP are an 8-tuple $\left(\left(x_{\tau}^{r}\right)_{\tau=R, M, P}, \lambda^{r}\right)_{r=\mathrm{BSP}, \mathrm{SP}}$, but the two budget balancing conditions $\lambda^{r}+1-\sum_{\tau} x_{\tau}^{r}, r=\mathrm{BSP}$, SP, reduce the total dimensionality by 2 . Thus, we compute Euclidean distance in $\mathbb{R}_{+}^{6}$ as opposed to $\mathbb{R}_{+}^{8}$.
} 


\section{Counterfactual Analysis}

In the political environment of the previous section, a policy profile $\left(x^{s}, \lambda^{s}\right)_{s \in \mathcal{R}}$ fails to be a PUNE if either the BSP or the SP can find a deviation that makes both of their two factions weakly better off and one faction strictly better off. In other words, for a party to deviate, its two factions must unanimously agree to a deviation. Earlier, we remarked that each PUNE may be regarded as a pair of bargaining solutions, one between the factions in each of the two parties. In fact, we can model PUNEs precisely as bargaining solutions in the sense of Nash (1950). This enables us to parameterize the two-dimensional manifold of equilibria and conduct a counterfactual analysis. We describe this procedure next.

Intra-Party Bargaining Theory. Suppose the Guardians and Venals of party $r=$ BSP, SP bargain over their party's policy, taking fixed the policy profile $\left(x^{s}, \lambda^{s}\right)_{s \in \mathcal{R} \backslash\{r\}}$ of the other three parties. If these two factions come to an agreement on policy $\left(x^{r}, \lambda^{r}\right)$ then the vote share of party $r$ within type $(\tau, \rho)$ is $\varphi_{\tau \rho}^{r}\left(x^{r}, x^{-r} ; \omega_{\tau \rho}\right)$, and the corresponding vote share for party $s \neq r$ is $\varphi_{\tau \rho}^{s}\left(x^{r}, x^{-r} ; \omega_{\tau \rho}\right)$. On the other hand, if the Guardians and Venals of party $r$ fail to come to an agreement, then their party offers no policy. In this case, the vote share of party $r$ is $\varphi_{\tau \rho}^{r}\left(0, x^{-r} ; \omega_{\tau \rho}\right)=0$ while the vote share of party $s \neq r$ is $\varphi_{\tau \rho}^{s}\left(0, x^{-r} ; \omega_{\tau \rho}\right)$. The "disagreement payoff" to the Venals of party $r$ is then 0 , since their party has a zero total vote share, and therefore does not extract any rents. The Guardians of party $r$, on the other hand, evaluate their disagreement payoff as being the average payoff to the voters who would have voted for them had they come to an agreement and offered policy $\left(x^{r}, \lambda^{r}\right)$. In other words, the disagreement payoff to the Guardians of party $r$ is

$$
Q^{r}\left(x^{r}, x^{-r}\right)=\sum_{\substack{(\tau, \rho) \in \mathcal{T} \\ s \in \mathcal{R} \backslash\{r\}}} \nu_{\tau \rho}\left(\varphi_{\tau \rho}^{s}\left(0, x^{-r} ; \omega_{\tau \rho}\right)-\varphi_{\tau \rho}^{s}\left(x^{r}, x^{-r} ; \omega_{\tau \rho}\right)\right)\left(\log x_{\tau}^{s}+b_{\rho}^{s}\right)
$$

As before, this reflects a form of reference-dependence: the disagreement payoff of the Guardians depends on a particular reference point $\left(x^{s}, \lambda^{s}\right)_{s \in \mathcal{R}}$, which determines the voting constituencies $\varphi_{\tau \rho}^{s}$ at which the Guardians evaluate their payoffs.

We say that a policy profile $\left(x^{s}, \lambda^{s}\right)_{s \in \mathcal{R}}$ is an intra-party bargaining solution (IPBS) if $\left(x^{\mathrm{INC}}, \lambda^{\mathrm{INC}}\right)$ and $\left(x^{\mathrm{BJP}}, \lambda^{\mathrm{BJP}}\right)$ are fixed at their values in Section 6 , and for each of the other two parties $r=\mathrm{BSP}, \mathrm{SP}$, there exists a number $\beta^{r} \in(0,1)$ such that $\left(x^{r}, \lambda^{r}\right)$ 
solves the following problem:

$$
\begin{gathered}
\max _{\left(\tilde{x}^{r}, \tilde{\lambda}^{r}\right)}\left(\Pi^{\mathcal{V} r}\left(\tilde{x}^{r}, \tilde{\lambda}^{r} ;\left(x^{s}, \lambda^{s}\right)_{s \in \mathcal{R}}\right)-0\right)^{\beta^{r}}\left(\Pi^{\mathcal{G} r}\left(\tilde{x}^{r}, \tilde{\lambda}^{r} ;\left(x^{s}, \lambda^{s}\right)_{s \in \mathcal{R}}\right)-Q^{r}\left(x^{r}, x^{-r}\right)\right)^{1-\beta^{r}} \\
\text { subject to } 0 \leq \tilde{\lambda}^{r}+\sum_{\tau} \nu_{\tau} \tilde{x}_{\tau}^{r} \leq 1, \tilde{\lambda}^{r} \geq 0, \tilde{x}_{\tau}^{r} \geq 0 \forall \tau \quad \text { (Bargain- } r \text { ) }
\end{gathered}
$$

where $Q^{r}\left(x^{r}, x^{-r}\right)$ is given in equation (17) above. The problem (Bargain- $r$ ) is precisely the generalized Nash bargaining problem adapted to our strategic setting. ${ }^{32}$ The problem states that the Venals and Guardians of party $r$ bargain to an agreement, taking as given the threat-points 0 and $Q^{r}\left(x^{r}, x^{-r}\right)$ respectively, as well as the policies offered by the other parties. Note that the problem (Bargain- $r$ ) treats the threat point of the Guardians of party $r$ as exogenously equal to $Q^{r}\left(x^{r}, x^{-r}\right)$. It also evaluates the payoffs of the two factions at the reference point $\left(x^{s}, \lambda^{s}\right)_{s \in \mathcal{R}}$. In other words, the solution $\left(x^{r}, \lambda^{r}\right)$ is a fixed point of the problem (Bargain- $r$ ); that is, when taken as generating the threat-point, it implies that the solution of the maximization is itself. Both the threat point of the Guardians, and the two factions' payoffs from a policy profile, are evaluated at the policy profile in which party $r$ 's policy solves the problem (Bargain- $r$ ). We then have the following duality theorem, which can be proven via an argument analogous to the proof of Theorem 8.2 in Roemer (2001).

Duality Theorem. A policy profile $\left(x^{s}, \lambda^{s}\right)_{s \in \mathcal{R}}$ is a PUNE iff it is an IPBS.

The first order conditions of the problem (Bargain- $r$ ) imply that if $\left(x^{s}, \lambda^{s}\right)_{s \in \mathcal{R}}$ is an IPBS, then both strategic parties, $r=$ BSP, SP must be using all of their budget; specifically, $\lambda^{r}+\sum_{\tau} \nu_{\tau} x_{\tau}^{r}=1$. We can use this fact to solve out for $\lambda^{r}$ in the remaining first order conditions. This, along with the fact that $\Pi_{\emptyset}^{\mathcal{G} r}=Q^{r}\left(x^{r}, x^{-r}\right)$ at the solution, implies that if $\left(x^{s}, \lambda^{s}\right)_{s \in \mathcal{R}}$ is an IPBS, then it satisfies the equations:

$$
\begin{aligned}
& \frac{\beta^{r} \nabla_{x} \Pi^{\mathcal{V} r}\left(x^{r}, 1-\sum_{\tau} \nu_{\tau} x_{\tau}^{r} ;\left(x^{s}, \lambda^{s}\right)_{s \in \mathcal{R}}\right)}{\Pi^{\mathcal{V} r}\left(x^{r}, 1-\sum_{\tau} \nu_{\tau} x_{\tau}^{r} ;\left(x^{s}, \lambda^{s}\right)_{s \in \mathcal{R}}\right)}+ \\
& \quad \frac{\left(1-\beta^{r}\right) \nabla_{x} \Pi^{\mathcal{G} r}\left(x^{r}, 1-\sum_{\tau} \nu_{\tau} x_{\tau}^{r} ;\left(x^{s}, \lambda^{s}\right)_{s \in \mathcal{R}}\right)}{\Pi^{\mathcal{G} r}\left(x^{r}, 1-\sum_{\tau} \nu_{\tau} x_{\tau}^{r} ;\left(x^{s}, \lambda^{s}\right)_{s \in \mathcal{R}}\right)-Q\left(x^{r}, x^{-r}\right)}=0, r=\text { BSP, SP }
\end{aligned}
$$

which are the simplified first order conditions of the bargaining problem (Bargain- $r$ ). Substituting (E-FOC) into (B-FOC), and solving for $\beta^{r}$ we obtain for each of the two

\footnotetext{
${ }^{32}$ It is generalized because the Guardians and Venals may not necessarily have equal bargaining abilities (i.e., $\beta^{r}$ may not necessarily equal 1/2) as in Nash's (1950) original formulation.
} 
strategic parties $r=\mathrm{BSP}, \mathrm{SP}$

$$
\beta^{r}=\frac{\Pi^{\mathcal{V} r}\left(x^{r}, \lambda^{r} ;\left(x^{s}, \lambda^{s}\right)_{s \in \mathcal{R}}\right)}{\Pi^{\mathcal{V} r}\left(x^{r}, \lambda^{r} ;\left(x^{s}, \lambda^{s}\right)_{s \in \mathcal{R}}\right)+\alpha^{r}\left[\Pi^{\mathcal{G} r}\left(x^{r}, \lambda^{r} ;\left(x^{s}, \lambda^{s}\right)_{s \in \mathcal{R}}\right)-Q\left(x^{r}, x^{-r}\right)\right]}
$$

where $\lambda^{r}=1-\sum_{\tau} \nu_{\tau} x_{\tau}^{r}$. In words, $\beta^{\mathrm{BSP}}$ and $\beta^{\mathrm{SP}}$ are the bargaining powers for the parties in the IPBS that correspond to the PUNE with associated Lagrangian multipliers $\alpha^{\mathrm{BSP}}$ and $\alpha^{\mathrm{SP}}$. Our counterfactual analysis uses the Duality Theorem, and this relationship that it implies, to (nearly) identify equilibria. Below, we describe and explain the exact procedure for this counterfactual analysis. We then report the results of the procedure.

Estimation Procedure. The detailed procedure of our counterfactual analysis is as follows. First, fix a particular vcPUNE, $\left(x^{s}, \lambda^{s}\right)_{s \in \mathcal{R}}$. (Recall that a vcPUNE, defined in Section 7, is "very close" to the "actual" policies of the BSP and SP depicted in the larger brighter dots of Figure 2.) Next, compute the disagreement payoffs $Q^{r}\left(x^{r}, x^{-r}\right)$ for the Guardians of each strategic party $r=\mathrm{BSP}$, SP, evaluated at this cPUNE. These are given by (17). Then use (18) to compute (again, at this particular vcPUNE) the relative bargaining abilities $\beta^{r}$ of the two factions of party $r=\mathrm{BSP}$, SP. Repeat this exercise for all vcPUNE. For each party $r=\mathrm{BSP}$, SP, define $\underline{\beta}^{r}$ and $\bar{\beta}^{r}$ to be the minimum and maximum values of $\beta^{r}$ across all vcPUNE.

Now, imagine a counter-factual world in which the U.P. voting population has no caste bias, but is otherwise the same as the factual voting population. In other words, set $b_{\rho}^{r}=0$ for all parties $r$ and all castes $\rho$, but leave all other parameters of the model unchanged, including the calibrated values of $f_{\tau \rho}^{r}$ and $d_{\tau \rho}$ in Table 7 . Using the procedure of Section 7, compute a large number of equilibria of this new model with no caste bias. Call the equilibria of the new model $\mathrm{PUNE}_{0} \mathrm{~s}$ to distinguish them from the PUNEs of the original model with caste bias. Then, for each $\mathrm{PUNE}_{0}$, use the procedure described in the previous paragraph to compute the relative bargaining abilities $\beta^{r}$ of Guardians and Venals of each strategic party $r=\mathrm{BSP}, \mathrm{SP}$. If $\beta^{\mathrm{BSP}} \in\left[\beta^{\mathrm{BSP}}, \bar{\beta}^{\mathrm{BSP}}\right]$ and $\beta^{\mathrm{SP}} \in\left[\underline{\beta}^{\mathrm{SP}}, \bar{\beta}^{\mathrm{SP}}\right]$, where $\underline{\beta}^{r}$ and $\bar{\beta}^{r}, r=\mathrm{BSP}, \mathrm{SP}$, are the minimum and maximum values of the relative bargaining abilities across the vcPUNE of the original model with caste bias, then call the $\mathrm{PUNE}_{0}$ that is associated with the pair $\left(\beta^{\mathrm{BSP}}, \beta^{\mathrm{SP}}\right)$ a vcPUNE $\mathrm{ve}_{0}$ The idea here is that so long as $\left[\underline{\beta}^{\mathrm{BSP}}, \bar{\beta}^{\mathrm{BSP}}\right]$ and $\left[\underline{\beta}^{\mathrm{SP}}, \bar{\beta}^{\mathrm{SP}}\right]$ are small intervals, vcPUNE $\mathrm{B}_{0}$ are exactly those equilibria of the new model in which the Guardians and Venals of each of the two strategic parties, BSP and SP, have nearly the same relative bargaining abilities as they do in the vcPUNEs of the original model. Since the Duality Theorem 

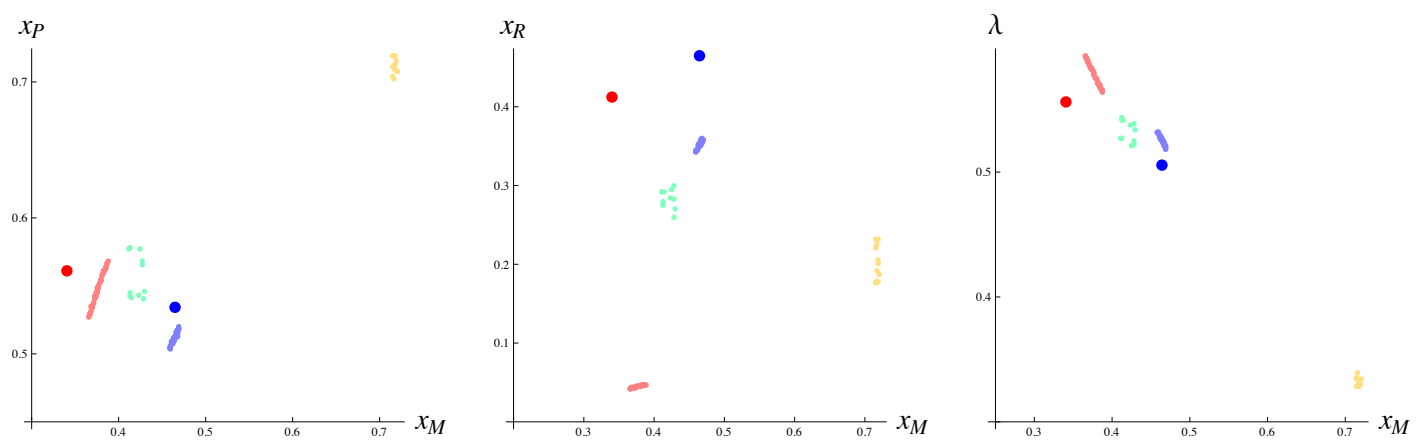

Figure 3. (a) [left] Projection of vcPUNEs and $\mathrm{vcPUNE}_{0} \mathrm{~s}$ onto the $x_{M}$ - $x_{P}$ plane. (b) [middle] Projection of vcPUNEs and vcPUNE 0 s onto the $x_{M}-x_{R}$ plane. (c) [right] Projection of vcPUNEs and $\mathrm{vcPUNE}_{0} \mathrm{~s}$ onto the $x_{M^{-}} \lambda$ plane. Larger brighter dots indicate the "actual" policies of the BSP and SP, in red and blue respectively. The scatter of smaller red dots are the BSP's policies in vcPUNEs while the scatter of yellow dots are the BSP's policies in vcPUNE ${ }_{0}$ s. The scatter of smaller blue dots are the SP's policies in vcPUNEs while the scatter of green dots are the SP's policies in vcPUNE $\mathrm{v}_{0} \mathrm{~s}$

enables us to conclude that equilibria vary continuously in relative bargaining abilities, this means that our model (and procedure for counterfactual analysis) can be used to estimate the effect of eliminating all caste bias in U.P. on the equilibrium policies of the strategic parties, and their equilibrium vote shares.

Estimates. Using the above procedure, we computed 13,063 candidates for $\mathrm{PUNE}_{0} \mathrm{~s}$, of which only 11 were $\mathrm{vcPUNE}_{0} \mathrm{~s}$. These $11 \mathrm{vcPUNE}_{0} \mathrm{~s}$ are depicted along with the 40 vcPUNEs and actual policies of the BSP and SP in Figure 3. Figure 3(a) on the left is the projection onto the $x_{M}-x_{P}$ plane, Figure $3(\mathrm{~b})$ in the middle is the projection onto the $x_{M}-x_{P}$ plane, and Figure 3(c) on the right is the projection onto the $x_{M}-\lambda$ plane. The larger brighter dots are the actual policies of the BSP and SP in red and blue respectively. The BSP's and SP's policies in vcPUNEs are the scatter of smaller red dots and smaller blue dots respectively. The BSP's and SP's policies in vcPUNE $\mathrm{V}_{0} \mathrm{~s}$ are the scatter of yellow and green dots respectively. The summary statistics for vcPUNE $\mathrm{v}_{0} \mathrm{~s}$ are also reported in the fourth row of Table 8.

Figure 3 and Table 8 indicate that in a world without caste bias, the BSP offers higher distribution shares to all three groups (the middle class, poor, and rich) and has a lower level of corruption. In particular, moving from a world with caste bias to a world without caste bias, the average distributions of the BSP to the rich, middle class and poor rise by 348.89\%, 90.69\% and 30.16\% respectively, while its corruption declines by $42.66 \%$. On the other hand, the distribution of the SP to poor rises, but its 
Table 9. Average Threat-points and Bargaining Abilities

\begin{tabular}{lcccccccc} 
& $Q^{\mathrm{BSP}}$ & $Q^{\mathrm{SP}}$ & $\beta^{\mathrm{BSP}}$ & $\beta^{\mathrm{SP}}$ & $\underline{\beta}^{\mathrm{BSP}}$ & $\bar{\beta}^{\mathrm{BSP}}$ & $\underline{\beta}^{\mathrm{SP}}$ & $\bar{\beta}^{\mathrm{SP}}$ \\
\hline \hline $\mathrm{vcPUNE}$ & -.359 & -3.374 & .899 & .033 & .848 & .949 & .032 & .034 \\
$\mathrm{vcPUNE}_{0}$ & -.146 & -3.984 & .912 & .033 & .892 & .929 & .032 & .034 \\
\hline
\end{tabular}

distribution to the rich and middle class declines. Also, on average the SP is slightly more corrupt. Specifically, moving from a world with caste bias to a world without caste bias, the average distribution of the SP to the rich and middle class decline by $19.89 \%$ and $9.68 \%$ respectively, while its average distribution to the poor rises by $8.78 \%$ and its average corruption rises by $1.52 \%$. So, while the BSP becomes much less corrupt in a world without caste bias, the SP on the other hand becomes slightly more corrupt. This is consistent with the logic of the simple analytical model presented in Section 3.

Table 9 reports additional information on vcPUNEs and $\mathrm{vcPUNE}_{0} \mathrm{~s}$. It shows the average threat-points of the Guardians of each of the two strategic parties, BSP and SP, across vcPUNEs and $\mathrm{vcPUNE}_{0} \mathrm{~s}$. According to the table, the average threat-point of the Guardians of the BSP increases, while the average threat-point of the Guardians of the SP decreases, as we move from reality to a world absent caste bias. More interestingly, the table indicates that the relative bargaining abilities of the Venals of the BSP are quite high across vcPUNEs (and thus across vcPUNE $\mathrm{s}_{0}$ ) while the relative bargaining abilities of the Venals of the SP are quite low. We conjecture that the high sensitivity of the BSP's corruption level in Figure 3(c) and Table 8 to changes in caste bias may be due to the fact that the BSP's Venals appear to be mostly in control of their party's policy in Table 9 (and it is the Venals who care about vote shares). Because the SP's policy is decided mostly by its Guardians (who care less about vote totals, and have relatively large bargaining power in Table 9) its corruption level is less sensitive to changes in caste bias.

\section{Discussion}

A research design like ours naturally relies on a number of simplifying assumptions and short-cuts. In particular, computational difficulties restrict us to simplifying political reality to a point where we lose many interesting features. This forces us to make 
judgments about which features we think will have the biggest (first order) effects, and are therefore worth retaining. We now conclude the paper with a discussion of some important omitted features, as well as other caveats and shortcomings.

Caste-targeted Policies. In our model, policies are targeted by class, but in recent years parties have started adopting policies that appear to be increasingly targeted by caste, despite the constitutional restrictions on such policies. However, despite the growth of small scale caste-targeted programs such as the Marriage Funding Program for OBC Girls and affirmative action policies ("reservations") in higher education, there is still the presumption that parties can really only affect the lives of the many millions of U.P. voters via their influence on large scale established programs like the Public Distribution System (PDS) and the Rural Employment Guarantee Scheme (REGS), both of which are targeted by class, not caste. For example, only 30 of the 2245 OBC individuals in our survey reported benefiting from the Marriage Funding Program (receiving an average grant of Rs. 8876), as compared to 3950 out of 4675 individuals who said that they benefited from the PDS, receiving numerous subsidies on everyday necessities such as foodstuffs and cooking fuel. Moreover, when we asked our respondents what the most useful government program was for them, the vast majority of individuals (specifically, 3276 respondents) reported a program that is primarily class-targeted. Finally, only 460 out of 4675 voting age individuals reported receiving any amount of higher education. This suggests that even the caste-based reservations in higher education are unlikely to touch the lives of the vast majority of U.P. voters who do not receive a higher education at all in the same way as programs like the PDS or REGS. Finally, it is well-known that the Indian Constitution places strict restrictions on the ability of governments to run social programs that are entirely targeted by caste. For these reasons, we choose to have policies that are class-targeted, and model the symbolic effects of caste-targeted policies on voters using the biases $b_{\rho}^{r}$.

Interpretation of Caste Biases. If the caste-based party biases $b_{\rho}^{r}$ are affected by parties' symbolic policies, as we discussed above, then why aren't they modeled as strategic choices? Our assumption that a party cannot change its caste affiliation is meant to reflect the idea that the parties have set their caste affiliations historically, and their current policies reflect these historical commitments rather than alter the current perceptions of the voters. Caste, in our model, has a role similar to valence in other models of political competition. It is something a candidate (or, here, party) can only work on improving or changing in the long term, and which influences voters, 
although it is not explicitly a policy.

For example, the fact that the BSP was founded on the social principles of B.R. Ambedkar and is led by Mayawati, a Dalit woman, or that the SP is led by Mulayam Singh Yadav, a member of the OBC category, or that the BJP was founded on a Hindu nationalism that appeals to General caste Hindus, are not things that parties can easily change over the course of one election. We assume that voters think of these historical facts when they think of a party's caste affiliation, and that parties cultivate their existing allegiances with particular castes rather than attempt to change their reputations in the course of a single election. That is why the $b_{\rho}^{r}$ are relatively immutable. Of course, parties may attempt to change their reputations over time. For example, in the 2007 State Assembly elections, the BSP had the highest percentage of Brahmin candidates of any major party (19\%) in an attempt to cultivate the Brahmin vote (and to some extent, they succeeded). But when we asked our respondents whether they would defect from their party to one that put up a candidate of their caste when their own party did not, only 1,048 individuals said they would consider it while 1,895 said they would not even consider it. This suggests that it is relatively difficult for a party to influence the values of $b_{\rho}^{r}$ in the course of a single election.

Other Forms of Corruption. We modeled corruption in this paper as the amount of public resources under a party's control that it embezzles. Of course, there are other forms of political corruption as well, such as electoral fraud and manipulation that are part of the reality of U.P. politics. Moreover, in our model corruption makes parties less attractive to voters; however, if the stolen money is used to buy votes, for example, then corruption may have the effect of improving the party's electoral prospects. These are important considerations that the model leaves out.

Voter Perceptions of Corruption and Policy. Our survey estimates of corruption and policy are based on our data of voters' perceptions, which vary widely, as indicated by the large standard deviations reported in Tables 4 and 5. One might think that because these standard deviations are so large, the parties are essentially indistinguishable. These large standard deviations might be due to the fact that answers to the corruption and distribution questions reflect, in part, the caste biases of the voters. For instance, respondents may take into account the fact that caste is correlated with class and be assigning a party's policy towards a particular caste. Alternatively, respondents who have a strong caste bias in favor of a particular party may report a lower perceived level of corruption for that party for psychological reasons. Since our 
data and model are based on subjective measures of policy, there is not much that we can do within the model to address these possibilities.

Changing Bargaining Powers. The skewed bargaining powers (the $\beta^{r}$ s) reported in Table 9 are interesting in their own right. The BSP's Venals are 8 times more powerful than the Guardians, and 7 times more powerful than SP's Venals are in their party. But it would be a mistake to interpret our results as saying that the BSP is generally more Venal than the SP. In the fictitious election circa 2008 that we model, we find that this assumption is most consistent with our data. We suspect that the fact that the BSP surprisingly got a majority of the seats in 2007 could be related to the BSP's caring much more about its vote share in 2007. In 2012, the SP received a majority of seats. So, we find it plausible that the influence of the Venals in their party increased significantly in the period between 2008 and 2012. Unfortunately, we do not have the data to estimate these changes.

Another modeling choice is that in the counterfactual analysis, when caste biases are eliminated, the relative bargaining powers of the Venals and Guardians do not change. This may not be a reasonable assumption, but we do not have a theory to determine the factional bargaining powers. Consequently, we suggest the following caveat: our counterfactual analysis should not be viewed as a full, general equilibrium analysis but rather only a partial equilibrium ceteris paribus analysis. We are studying the influence of caste bias on policy, holding fixed the factional bargaining powers.

The BJP and INC as non-Strategic Parties. Another reason to view our analysis as only a partial equilibrium analysis is that we have treated the INC and BJP as nonstrategic parties, even though their corruption levels probably also vary with caste and other issues that we have not modeled (such as the extent of Hindu nationalism and the place of Muslims in Indian society). Unfortunately, the model becomes intractable when we make these parties strategic as well.

Religious Bias. Our model has focused on caste bias at the expense of religious bias. In particular, we have ignored the importance of Hindu-Muslim tensions in U.P. politics, which have been studied by a rich previous literature on India (Brass 2003; Varshney 2002; Wilkinson 2004). While we believe that these tensions are more salient in national level politics in U.P. (i.e., elections to the Lok Sabha in New Delhi) than in state level politics, where we argued that caste has become the most salient noneconomic issue, we think it is worthwhile for future empirical research to consider 
religious and other electoral motivations such as nationalism, which are obviously very important elements of Indian politics. 


\section{References}

[1] Banerjee, Abhijit and Rohini Pande (2011). "Parochial Politics: Ethnic Preferences and Politician Corruption," mimeo, Harvard Kennedy School.

[2] Bhavnani, Rikhil (2013). "A Primer on Voter Discrimination Against India's Lower Caste Politicians: Evidence from Natural and Survey Experiments," working paper.

[3] Brass, Paul (2003). The Production of Hindu-Muslim Violence in Contemporary India, Seattle: University of Washington Press.

[4] Chandra, Kanchan (2004). Why Ethnic Parties Succeed: Patronage and Ethnic Headcounts in India, Cambridge, UK: Cambridge University Press.

[5] Deliège, Robert (1999). The Untouchables of India, Ann Arbor, MI: the University of Michigan Press.

[6] Duggan, John (2012). "A Survey of Equilibrium Analysis in Spatial Models of Elections," mimeo, University of Rochester.

[7] Dunning, Thad and Janhavi Nilekani (2013). "Ethnic Quotas and Political Mobilization: Caste, Parties, and Distribution in Indian Village Councils," American Political Science Review, 107:1:35-56.

[8] Franck, Raphaël and Ilia Rainer (2012). "Does the Leader's Ethnicity Matter? Ethnic Favoritism, Education and Health in Sub-Saharan Africa," American Political Science Review, 106:2:294-325.

[9] Jaffrelot, Christophe (2003). India's Silent Revolution: The Rise of Lower Castes in North India, London: Hurst \& Co.

[10] Jain, Ravindra K. (1996). "Hierarchy, Hegemony and Dominance: Politics of Ethnicity in Uttar Pradesh, 1995," Economic and Political Weekly, pp. 215-223.

[11] Kőszegi, Botond and Matthew Rabin (2006). "A Model of Reference-Dependent Preferences," The Quarterly Journal of Economics, 121:4:1133-65.

[12] Kramon, Eric and Daniel Posner (2012). "Ethnic Favoritism in Primary Education in Kenya," typescript.

[13] Kumar, Sanjay (2004). "Increasing Fluidity in Electoral Contests: Is This Mere Anti-Incumbency?" in R. Vora and S. Palshikar (eds.) Indian Democracy: Meanings and Practices, New Delhi: Sage. 
[14] Lee, Alexander (2013). "The Political Economy of Caste: Party, Identity and Public Spending in India," mimeo, Stanford University.

[15] Lindbeck, Assar and Jorgen Weibull (1987). "Balanced-Budget Redistribution as the Outcome of Political Competition," Public Choice, 52:3:273-97.

[16] Nash, John (1950). "The Bargaining Problem," Econometrica, 18:2:155-62.

[17] Roemer, John E. (2001). Political Competition: Theory and Applications, Cambridge, MA: Harvard University Press.

[18] Roemer, John E. (1999) "The Democratic Political Economy of Progressive Income Taxation," Econometrica, 67:1:1-19.

[19] Sridharan, E. (2002). "The Fragmentation of the Indian Party System, 1952-1999" in Zoya Hassan (ed.) Parties and Party Politics in India, Oxford.

[20] Vaishnav, Milan (2012). "Caste Politics, Credibility and Criminality: Political Selection in India," memo, University of Pennsylvania.

[21] Varshney, Ashutosh (2002). Ethnic Conflict and Civic Life: Hindus and Muslims in India, New Haven: Yale University Press.

[22] Wilkinson, Steven (2004). Votes and Violence: Electoral Competition and Ethnic Riots in India, Cambridge University Press.

[23] Yadav, Yogendra (2000). Understanding the Second Democratic Upsurge: Trends of Bahujan Participation in Electoral Politics in the 1990s, Transforming India: Social \& Political Dynamics of Democracy. 